\title{
Do Hedge Funds Manipulate Stock Prices?
}

\author{
Itzhak Ben-David \\ Fisher College of Business, The Ohio State University \\ Francesco Franzoni \\ Swiss Finance Institute and University of Lugano \\ Augustin Landier \\ Toulouse School of Economics \\ Rabih Moussawi \\ Wharton Research Data Services, The Wharton School, University of Pennsylvania
}

February 2011

\begin{abstract}
We find evidence of significant price manipulation at the stock level by hedge funds on critical reporting dates. Stocks in the top quartile by hedge fund holdings exhibit abnormal returns of 30 basis points in the last day of the month and a reversal of 25 basis points in the following day. Using intraday data, we show that a significant part of the return is earned during the last minutes of the last day of the month, at an increasing rate towards the closing bell. This evidence is consistent with hedge funds' incentive to inflate their monthly performance by buying stocks that they hold in their portfolios. Higher manipulations occur with funds that have higher incentives to improve their ranking relative to their peers and a lower cost of doing so.
\end{abstract}

\footnotetext{
* We thank Alessandro Beber, Bruno Biais, YeeJin Jang, Gulten Mero, Tarun Ramadorai, David Thesmar, and conference participants of the $3^{\text {rd }}$ Annual Hedge Funds Conference in Paris for helpful comments.
} 
"If I were long and I would like to make things a little bit more rosy, I'd go in and take a bunch of stocks and make sure that they are higher.... A hedge fund needs to do a lot to save itself."

Jim Cramer, ex-hedge fund manager, in an interview to TheStreet.com, December 2006

\section{Introduction}

As arbitrageurs, the economic function of hedge funds is to bring prices closer to fundamentals. This paper shows that this role is partly betrayed by hedge funds' incentive to maximize fees. In particular, we provide evidence suggesting that hedge funds are likely to pump up end-of-month stock prices in order to improve their performance. Based on the holdings data of hedge funds in conjunction with daily and intraday stock price data, we find that prices of stocks with high hedge fund ownership exhibit abnormal positive returns in the last minutes of trading on the last day of the quarter and that they rebound the following morning. To illustrate the effect, stocks in the top quartile holdings by hedge funds exhibit an average abnormal return of 30 basis points in the last day of the month; these returns slip back by 25 basis points on average in the following day. Further, these patterns are strongest when hedge fund owners have incentives to manipulate: less diversified funds (for which manipulating is less costly), funds experiencing a poor month in terms of absolute returns, and funds that are among the highest year-to-date performers and wish to benefit by attracting investors' attention.

Hedge funds typically report performance figures to their investors on a monthly frequency. Several studies have raised doubts about the reliability of these reports, as hedge funds have an incentive to modify their numbers in order to attract greater flows. Specifically, investors judge hedge funds according to their risk adjusted performance (Asness, Krail, and Liew 2001); a highly negative return will thus leave a lasting stain on a fund's track-record. Hedge funds have a further incentive to manipulate reporting, as their fees are typically tied to performance. Consistent with these motives to manipulate, Bollen and Pool (2009) document a discontinuity in the total returns distribution of hedge funds around zero, which is suggestive of manipulation. Also, Bollen and Pool (2008) present evidence that hedge fund total returns are more strongly autocorrelated when conditioned on past performance, potentially suggesting that returns are manipulated. Agarwal, Daniel, and Naik (2009) document that the December total 
returns of hedge funds are significantly higher than returns in other months; they suggest this might be a result of manipulation. Cici, Kempt, and Puetz (2010) compare the equity prices that hedge funds report on their 13F filings to prices on CRSP, and find that the prices on the 13F forms are higher on average. ${ }^{1}$ The alternative explanation for some of these results is that many assets held by hedge funds are illiquid, and therefore their valuations could be imprecise, with the autocorrelation due to fundamental reasons, as opposed to mere window dressing (Getmansky, Lo, and Makarov 2004).

Manipulation of end-of-month prices by hedge funds is likely to have wider welfare consequences beyond the jamming of hedge fund performance signal. Specifically, many players in the economy use end-of-month stock prices in contracting. For example, some executive compensation contracts are based on stock price performance. Also, asset manager compensation fees and asset manager rankings (e.g., mutual funds) are based on monthly performance. Thus, adding noise to stock returns by hedge funds distorts other contract signals and thus imposes a negative externality in aggregate. Though the distortion induced by hedge funds' manipulation is shown to revert quickly, we show that it does not net to zero within the month, i.e., a stock whose price decreased due to a reversal on the first day of the month is not likely to be manipulated again at the end of the month. More broadly, our paper joins prior literature documenting end-of-day security price manipulation in other contexts. Carhart, Kaniel, Musto, and Reed (2002) document that the prices of stocks owned by mutual funds exhibit positive abnormal returns at the end of the quarter. Ni, Pearson, and Poteshman (2005) report that stocks tend to cluster around option strike prices on expiration dates. Blocher, Engelberg, and Reed (2010) show that short sellers put down pressure on prices at the last moments of trading before the end of the year.

Our study uses a comprehensive dataset of hedge fund holdings. This dataset is a combination of $13 \mathrm{~F}$ mandatory filing of quarterly equity holdings for institutional investors and a proprietary list of hedge funds from Thomson-Reuters. In addition, we use hedge fund

\footnotetext{
${ }^{1}$ Other studies examine stock market manipulation through a broader scope. Aggarwal and Wu (2006) discuss spreading rumors and analyze SEC enforcement actions to show that manipulations are associated with increased stock volatility, liquidity, and returns. Allen, Litov, and Mei (2006) present evidence that large investors manipulate prices of stocks and commodities by putting pressure on prices in their desired direction; as a result, prices are distorted and have higher volatility.
} 
characteristics data from TASS and intraday data from TAQ. Together, these data allow us to have a close look at hedge funds' portfolios at a quarterly frequency and to examine trades on these stocks around the turn of the quarter. Note that, while we conjecture that manipulation takes place on a monthly frequency when hedge funds report their results, we are bound by the quarterly frequency of the data.

Our study has two parts. First, we document that stocks held by hedge funds at the end of the quarter are likely to experience large abnormal returns on the last trading day. This effect is statistically and economically significant: stocks at the top quartile of hedge fund ownership earn, on average, abnormal return of $0.30 \%$ on the last day of the quarter, most of which reverts the next day. Moreover, about half of the average increase in prices of stocks that are owned by hedge funds takes place in the last 20 minutes of trade, and reverts in the first ten minutes of trade in the following day. The effect exists at the monthly level, although our precision is lower at this frequency due to data frequency limitations.

Our evidence suggests that particular stocks are affected more than others. Consistent with the idea that limited capital is devoted to pushing stock prices, we find that among stocks held by hedge funds, illiquid stocks exhibit larger price increases on the last day of the quarter. Importantly, we show that at the stock-month level, the effect does not cancel out; i.e., the stocks that experience an end-of-month price surge because of manipulation are not likely to have experienced a reversal at the beginning of the same month. That is to say, manipulation does not occur on the same stocks every month.

In the second part of the paper, we analyze the characteristics of hedge funds whose equity portfolios exhibit an abnormal positive return at the end of the quarter and a decline on the next day. We document that small hedge funds with concentrated portfolios are more likely to be associated with manipulation patterns. We find that manipulating hedge funds rank at the top in terms of year-to-date performance. These results are consistent with the evidence in Carhart, Kaniel, Musto, and Reed (2002) that mutual funds that manipulate stock prices are those with the best past performance. They argue that, given a convex flow-performance relation for mutual funds (Ippolito 1992, Sirri and Tufano 1998), the best performers have the strongest incentive to manipulate. We believe that a similar explanation applies to hedge funds. We also report that manipulation patterns are persistent at the fund level, i.e., funds that have manipulated in the past 
are more likely to do so in the future. Finally, we document that manipulation patterns exist consistently throughout the sample period between 2000 and 2009. However, they are stronger in quarters in which market returns were low, potentially because these episodes are opportunities for hedge funds to demonstrate their skill to investors.

We run a battery of robustness checks to rule out alternative explanations for our findings. First, we perform a feasibility test, in which we show that for stocks in the bottom half of the liquidity spectrum, a price change of one percent is associated with volume of less than $\$ 500,000$. This means that manipulation by small hedge funds is potentially plausible for illiquid stocks. Second, we test whether our documented effect is not generated mechanically by portfolio reallocation, resulting either from asset inflows or rebalancing. When we lag our hedge fund holding measure by one month or control for current and future inflows, the relation remains strong. Third, there is no overlap with price manipulations by mutual funds such as those documented by Carhart, Kaniel, Musto, and Reed (2002). We conclude that the latter two alternative explanations are not likely to be responsible for the price regularities.

The paper proceeds as follows. Section 2 describes the data sources used. Section 3 develops the hypotheses about the incentive and methods to manipulate security prices, while Section 4 presents the daily and intraday empirical evidence about end-of-month manipulations and relates it to stock characteristics. Section 5 takes a close look at the determinants of hedge fund behavior and investigates cross-sectional heterogeneity in the exposure to these determinants. Section 6 assesses the feasibility of stock manipulation using price impact regressions, and Section 7 concludes.

\section{Data Sources and Sample Construction}

\subsection{Hedge Fund Holding Data}

The main dataset used in the study combines a list of hedge funds provided by ThomsonReuters, mandatory institutional quarterly portfolio holdings reports (13F), and information about hedge fund characteristics and performance (TASS). The same dataset, only for a shorter period, was used by Ben-David, Franzoni, and Moussawi (2010). 
13F mandatory institutional reports are filed with the SEC on a calendar quarter basis and are compiled by Thomson-Reuters (formerly known as the 13F CDA Spectrum 34 database). ${ }^{2}$ Form 13F requires all institutions with investment discretion over \$100 million of qualified securities (mainly publicly traded equity, convertible bonds, and options) at the end of the year to report their long holdings in the following year. ${ }^{3}$ Therefore, all hedge funds with assets in qualified securities that exceed a total of $\$ 100$ million are required to report their holdings in $13 \mathrm{~F}$ filings. $13 \mathrm{~F}$ reporting is done at the consolidated management company level. ${ }^{4}$

We then match the list of $13 \mathrm{~F}$ institutions in Thomson-Reuters with a proprietary list of 13F hedge fund managing firms and other institutional filers provided by Thomson-Reuters. Relative to the self-reported industry lists that are commonly used to identify hedge funds, the Thomson-Reuters list is certainly more comprehensive, as it classifies all $13 \mathrm{~F}$ filers. ${ }^{5}$ Moreover,

\footnotetext{
${ }^{2}$ According to Lemke and Lins (1987), Congress justified the adoption of Section 13F of the Securities Exchange Act in 1975 because, among other reasons, it facilitates consideration of the influence and impact of institutional managers on market liquidity: "Among the uses for this information that were suggested for the SEC were to analyze the effects of institutional holdings and trading in equity securities upon the securities markets, the potential consequences of these activities on a national market system, block trading and market liquidity....”

${ }^{3}$ With specific regard to equity, this provision concerns all long positions greater than 10,000 shares or $\$ 200,000$ over which the manager exercises sole or shared investment discretion. The official list of Section 13F securities can be found at: http://www.sec.gov/divisions/investment/13Flists.htm. More general information about the requirements of Form 13F pursuant to Section 13F of the Securities Exchange Act of 1934 can be found at: http://www.sec.gov/divisions/investment/13Ffaq.htm.

${ }^{4} 13 \mathrm{~F}$ filings were used intensely in research concerning the role of institutional investors in financial markets. Brunnermeier and Nagel (2004) explore the behavior of hedge funds during the Internet bubble. Campbell, Ramadorai, and Schwartz (2009) combine 13F filings with intraday data to explore the behavior of institutional investors around earnings announcements.

${ }^{5}$ This comprehensiveness depends on Thomson's long-lasting and deep involvement with institutional filings. The SEC has long contracted the collection of various institutional data out to Thomson-Reuters, even when those reports were paper filings or microfiche in the public reference room. They also have directories of the different types of institutions, with extensive information about their businesses and staff. The list of hedge funds to which we have access is normally used by Thomson-Reuters for their consulting business and, to the best of our knowledge, has not been provided to other academic clients. References to Thomson-Reuters (or the companies that it acquired, such as CDA/Spectrum, formerly known as Disclosure Inc. and Bechtel) can be found at:

1. http://www.sec.gov/rules/final/33-8224.htm (search for Thomson);
} 
the Thomson-Reuters hedge fund list identifies hedge funds at the disaggregated advisor level, not at the $13 \mathrm{~F}$ report consolidated level. For example, for Blackstone Group holdings in 13F data, Thomson-Reuters provided us with a classification of each of the advisors within Blackstone that reported their holdings under the same filing. ${ }^{6,7}$ Overall, our access to ThomsonReuters’ proprietary list of hedge funds puts us in a privileged position.

The 13F data available to us range from 1989Q3 to 2009Q4. Before applying the filters described below, the number of hedge funds in the Thomson-Reuters list varies from a few dozen in the early years to over 1,000 at the 2007 peak. We cross-check our list of hedge funds with the FactSet database and we find it congruent with the FactSet LionShares identification of hedge fund companies. With some caveats that we mention below, an additional advantage of the $13 \mathrm{~F}$ filings is that they are not affected by the selection and survivorship bias that occurs when relying on TASS and other self-reported databases for hedge fund identification (Agarwal, Fos, and Jiang 2010).

Data in the $13 \mathrm{~F}$ filings have a number of known limitations. First, small institutions that fall below the reporting threshold (\$100 million in qualified 13(f) securities, which include US equities, ADRs, ETFs, convertible bonds, and equity options) at the end of the year are not in the sample in the following year. Second, we do not observe all positions that do not reach the threshold of $\$ 200,000$ and 10,000 shares. Third, short equity positions are not reported. Fourth, the filings are aggregated at the management company level, but as mentioned above, the

2. SEC Annual Reports, 1982, http://www.sec.gov/about/annual_report/1982.pdf (page 37, or 59 of the pdf file);

3. http://www.sec.gov/rules/final/33-7432.txt (search for contractor);

4. http://www.sec.gov/about/annual_report/1989.pdf (search for contractor).

${ }^{6}$ There are three advisor entities within Blackstone Group L.P. that report their holdings in the same consolidated Blackstone Group report. Among the three advisors included, GSO Capital Partners and Blackstone Kailix Advisors are classified by Thomson-Reuters as Hedge Funds (which an ADV form confirms), while Blackstone Capital Partners V LP is classified as an Investment Advisor. See the "List of Other Included Managers" section in the September 30, 2009, Blackstone 13F reports filed on November 16, 2009:

http://www.sec.gov/Archives/edgar/data/1393818/000119312509235951/0001193125-09-235951.txt

${ }^{7}$ For brevity, we will from now on refer to the observational unit in our data set as a 'hedge fund'. It should be clear, however, that $13 \mathrm{~F}$ provides asset holdings at the management firm level or at the advisor entity level. Each firm/advisor reports consolidated holdings for all the funds that it has under management. 
Thomson classification allows us to separately identify the advisors within a management company. Fifth, we only observe end-of-quarter snapshots on hedge fund holdings. In spite of these limitations, it must be stressed that our data is not plagued by survivorship bias as it also contains the filings of defunct hedge fund firms.

Because many financial advisors manage hedge-fund-like operations alongside other investment management services, we need to apply a number of filters to the data to ensure that, for the institutions captured in our sample, the main line of operation is a hedge fund business. To this end, we drop institutions that have many advisors who have a majority of non-hedge fund business, even though they have hedge funds that are managed in-house and included with their holdings in the parent management company's 13F report. Thomson-Reuters' hedge fund list also provides the classification of non-hedge fund entities that file under the same 13F entity. We use this list to screen out all companies with other reported non-hedge fund advisors that file their $13 \mathrm{~F}$ holdings along with their hedge funds. Additionally, we manually verify that large investment banks and prime brokers that might have an internal hedge fund business are excluded from our list (e.g., Goldman Sachs Group, JP Morgan Chase \& Co., American International Group Inc.). As a further filter, we double-check the hedge fund classification by Thomson-Reuters against a list of ADV filings by investment advisors since 2006, when available. ${ }^{8}$ We match those filings by advisor name to our $13 \mathrm{~F}$ data. Then, following Brunnermeier and Nagel (2004) and Griffin and Xu (2009), we keep only the institutions with more than half of their clients classified as "High Net Worth Individuals" or "Other Pooled Investment Vehicles (e.g., Hedge Funds)” in Item 5.D (Information About Your Advisory Business) of Form ADV. Therefore, we believe that our final list of hedge funds contains only institutions with the majority of their assets and reported holdings in the hedge fund business, which we label these “pure-play” hedge funds.

\footnotetext{
${ }^{8}$ ADV forms are filed by investment advisors. In these forms, advisors provide information about the investment advisor's business, ownership, clients, employees, business practices, affiliations, and any disciplinary events for the advisor or its employees. The ADV filings were mandatory for all hedge funds only for a short time in 2006. In the later period, they were filed on a voluntary basis. All current advisor ADV filings are available on the SEC's investment advisor public disclosure website:

http://www.adviserinfo.sec.gov/IAPD/Content/Search/iapd_OrgSearch.aspx.
} 
We augment our data with hedge fund characteristics and monthly returns from the Thomson-Reuters’ Lipper-TASS database (drawn in July 2010). ${ }^{9}$ We use both the "Graveyard” and "Live" databases. ${ }^{10}$ We use hedge fund company names in TASS and map them to the advisor company name that appears in the $13 \mathrm{~F}$ filings. The Lipper-TASS database provides hedge fund characteristics (such as investment style and average leverage) and monthly return information at the strategy level. We aggregate the TASS data at the management company level, on a quarterly frequency, and match it to the $13 \mathrm{~F}$ dataset using the consolidated management company name. ${ }^{11}$ We exclude hedge funds with total assets under management of less than \$1 million, in order to ensure that our results are not driven by hedge funds with insignificant holdings. As argued in the introduction, we focus on the years surrounding the recent financial crisis and let our sample start in the first quarter of 2004. The sample-end coincides with the end of 13F data availability (2009Q4). Finally, for the fund level regressions, we winsorize fund flows and changes in hedge fund equity holdings at the $5^{\text {th }}$ and $95^{\text {th }}$ percentiles within each quarter, as the distributions of these variables have fat tails.

We refer to Panel A of Table 1 in Ben-David, Franzoni, Moussawi (2010) for annual statistics on our sample of hedge funds.

\subsection{Daily Stock Returns and Stock Characteristics}

For daily stock returns and stock characteristics we use standard databases: CRSP and Compustat. We limit our sample to January 2000 through September 2010.

\footnotetext{
${ }^{9}$ While we use the most recent TASS data feed for hedge fund information (July 2010), we use an older version (August 2007) to identify firms (as it included hedge fund names).

${ }^{10}$ TASS starts retaining information on 'dead' funds only from 1994, while our analysis starts in 1990 . We have run the regressions that use TASS data excluding the period before 1994; the results are largely unaffected. The reason for this is likely because most of our crisis periods occur after 1994.

${ }^{11}$ We used strategy assets under management as weights in aggregating fund characteristics and total reported returns.
} 


\subsection{NYSE TAQ Data for Intraday Trades}

We use the TAQ intraday trades dataset to calculate intraday return and volume information during several intervals within each trading day. We have 30 minute intervals between 9:30AM and 3PM, and 10 minute intervals between 3PM and 4PM. To do that, we first drop the corrected trades and all trades with conditions O, B, Z, T, L, G, W, J or K (e.g., bunched trades, trades outside trading hours). Then, we keep only the trades without missing size and price information, as long as they are made before $4 \mathrm{pm}$ or before a closing price (trade condition of 6, @6, or M) is generated. Interval returns are computed as the difference between the price of the last trade during the interval, and the last trade price before the start of the interval. If there were no trades during the interval, then the interval return is set to zero. Interval volume is computed as the sum of all dollar volume for all trades during the interval, and is equal to zero if there were no trades.

For the price impact of trading analysis (Section 6), we use TAQ trading data for January 2000 until September 2010. We keep only data for the last day of the month and the last ten seconds of trade. Over each second, we consolidate the dollar amount of trades, as well as compute the return.

\section{Development of the Hypotheses}

Contract theory predicts that agents try to strategically manipulate to their advantage the signals that are used by principals to evaluate their talent or their real performance (Holmström 1999, Holmström and Milgrom 1991). Hedge funds report monthly returns to their current investors; the track record they use to attract new capital is also based on monthly returns. It follows that they have incentives to manipulate their short-term performance as long as the expected costs do not exceed the benefits. Manipulating stock prices at month-end in order to boost monthly performance could be beneficial for some hedge funds because it allows them to avoid a highly negative return that would tarnish their track-record or because, by being ranked higher, they can potentially attract more capital and thus collect more fees. The costs of manipulation presumably include primarily transaction costs and the risk of detection and legal indictment. Since the signal that hedge funds try to manipulate to their advantage is their monthly return, manipulation could be expected to happen at the very end of the month. This 
timing derives from two sources: first, to be effective, the manipulation needs to last until month end; beginning a manipulation earlier would be unnecessarily costly. Moreover, funds know only toward the month-end whether manipulating in a given month is advantageous (e.g. depending on their monthly performance), and thus should exercise the option to manipulate later rather than sooner.

There is some anecdotal evidence for manipulation in the hedge funds industry. In an interview with TheStreet.com (cited as the epigraph), ${ }^{12}$ ex-hedge fund manager Jim Cramer describes how his hedge fund used to manipulate security prices in order to improve performance towards paydays. Importantly, Mr. Cramer suggests that \$5 or \$10 million dollars are sufficient to move stock prices substantially enough to achieve profit goals and "foment the impression" that the fund is successful.

Our first hypothesis, therefore, is that stock prices held in hedge funds' portfolios exhibit returns that are abnormally higher towards the end of the month. Since the returns are a result of price pressure, we conjecture that prices revert following the turn of the month:

H1: Stocks held by hedge funds exhibit:

a. Abnormal positive returns towards the end of the month,

b. Abnormal negative returns following the turn of the month.

We propose that manipulated stocks are more likely to be relatively illiquid. For these stocks, the bang-for-the-buck is higher, and therefore can be manipulated at lower cost. This prediction is consistent with Comerton-Forde and Putnins (2010), who suggest that illiquid stocks with a high degree of information asymmetry are most prone to manipulation. Therefore:

H2: Illiquid stocks are more likely to be manipulated.

Next, we wish to characterize those hedge funds that engage in manipulation activity. We conjecture that manipulation is more likely for hedge funds with less diversified portfolios. For these hedge funds, the payoff for manipulating stocks has a higher impact on performance results. Further, we speculate that small hedge funds are more likely to engage in manipulation, as it is easier for them to improve portfolio results by limited, undetected, manipulation.

${ }^{12}$ http://www.liveleak.com/view?i=b1b_1237128864 


\section{H3: Manipulation is more likely for:}

\section{a. Hedge funds with undiversified portfolios,}

b. Small hedge funds.

We also analyze the incentives that lead hedge funds to manipulate stock prices. For hedge funds, the month's, quarter's, and year's ends are important dates for two reasons. First, hedge fund fees are paid based on past performance, typically measured at the end of these periods. Second, hedge funds, like mutual funds, care deeply about their performance ranking, as investors often select funds based on their past performances. Empirically, it is difficult to separate the two incentives in the data because fees are increasing in performance for all firms.

Nevertheless, there are hedge funds that value improved rankings more than others: top performing funds may manipulate stock returns more than others, potentially because they are competing for the highest positions on the list. This conjecture follows Carhart, Kaniel, Musto, and Reed (2002), who find similar results for mutual funds. More finely, within the top performers, hedge funds that were bad performers in a previous quarter but that had caught up with their peers might have more incentives to attract investors' attention. Funds that had a low YTD (Year-to-Date) ranking in the past quarter but that now have a high YTD ranking might be especially eager to boost earnings in order to get noticed by investors and potentially be "recategorized" from losers to winners.

Certain circumstances are likely to make investors' impression of a fund more elastic, and to increase the sensitivity of their flows to prior performance. For example, investors' belief regarding young funds might be more elastic to performance due to the funds' shorter track records. Thus young funds should be more prone to manipulate when they are doing well, so as to maximize investors' reaction to a good performance. In addition, earlier in the year, relative year-to-date performance rankings are more elastic to monthly performance. Finally, hedge funds may gain more exposure if they exhibit an atypical performance when the market performs poorly. This is consistent with Asness, Krail, and Liew (2001), who conjecture that hedge funds attempt to appear to be performing well in a down market to signal their skill.

We explore the hypothesis that the magnitude of the manipulation is related to recent performance of the stock market, as investors may benchmark hedge fund performance relative 
to the performance of the market. Specifically, a major reason for institutional investors to invest in hedge funds is to diversify away from systematic risk. Thus, to attract and keep capital, hedge funds need to prove that they can offer strong protection against market downturns. It is thus valuable for them to display relatively stronger returns when the market is doing poorly. For this reason, we expect that on average, hedge funds will be more prone to manipulation in months when the market performs poorly.

To summarize, we conjecture that:

H4: Manipulation aimed at boosting performance rankings is stronger for:

a. Top performing hedge funds,

b. Hedge funds with currently good but a poor past relative performance,

c. Young hedge funds,

d. Earlier in the calendar year,

e. When market returns are low.

We expect to observe persistence in manipulating behavior over time. Persistence may arise for several reasons. The first is purely statistical: it is likely that only some (rather than all) funds engage in this practice. For instance, some funds might have internal risk-management standards that ban it. For the econometrician, a blip observed in a given quarter is a signal that a fund is more likely to belong to the "manipulating" category. Thus, conditional on observing a "blip” at quarter-end $t$, a fund is statistically more likely to exhibit a "blip” next period. A second reason for persistence is that once a fund has manipulated returns for strategic purposes, it might be tempted to continue to "undo" the negative impact of the previous quarter's manipulation on this quarter's performance.

H5: Manipulation activity is persistent over time at the hedge fund level.

Finally, we conduct a feasibility analysis. In keeping with the Cramer's interview, we propose that the manipulation must be feasible for small hedge funds, i.e., moving stock prices before the closing does not require much capital.

H6: Traders can move prices at the end of the month by investing relative small amounts of capital. 
In the next sections, we analyze the data and seek confirmation for these hypotheses.

\section{Evidence of End-of-Quarter Manipulation}

\subsection{Evidence from Daily Returns}

Our goal is to test whether hedge funds manipulate the price of the stocks in their portfolio at the end of the quarter. Using $13 \mathrm{~F}$ information, for each stock and quarter we compute the fraction of market capitalization that is held by hedge funds. Next, we construct an indicator variable which equals one if, for a given stock-quarter, the share of hedge fund ownership is above the median. The median ownership by hedge funds across quarters is $1.3 \%$.

Our initial approach focuses on the four months that correspond to quarter ends (March, June, September, and December) so that the $13 \mathrm{~F}$ information is mostly up to date in terms of hedge funds' end-of-month ownership. In Table 2, we regress the daily stock return in the four days around the quarter end (the second-to-last, last, next-to-last, and second-after-the-last days of the quarter) onto the high hedge fund ownership dummy. Percentage returns are risk-adjusted using the Daniel, Grinblatt, Titman, and Wermers (1997, DGTW) approach. Standard errors are clustered at the date level in these regressions as well as the other stock level regressions in this section.

Panel A of Table 2 shows a strong pattern in the last day of the quarter as well as a reversal in the following day (the first day of the following quarter). Stocks at the top ownership quartile increase on average by 30 bps (basis points) on the last day of the quarter, and decrease by 25 bps in the following day. The panel shows that there is no effect in the second-to-last day of the quarter or in the second day of the next quarter. This is the first piece of evidence consistent with Hypothesis H1a, indicating that hedge funds may be pumping up the price of stocks they own. Consistent with the reversion of a pure price pressure effect, the return is significantly more negative for the same stocks on the following day (consistent with Hypothesis H1b). Panel B performs a similar analysis, where the stock universe is split by half according to the ownership by hedge funds. Stock with hedge fund ownership of above the median experience an average increase of 18 bps on the last day of the quarter and an average reversal of 14 bps in the following day. 
In Table 3, we break down the previous result by quarter. The end-of-month price surge for high hedge fund ownership stocks seems to increase over the course of the year. However, the fund level evidence which we present below indicates that the impact on fund returns remains stable throughout the year (see Table 7).

The relation between end-of-month returns and hedge fund ownership raises a few concerns about omitted variables. Table 4 presents robustness tests for some of these possibilities. One potential interpretation of our results is that the observed price spikes for stocks that are owned by hedge funds are due to portfolio reallocation at the end of the month rather than intentional price manipulation. Hence, it could be that high hedge fund ownership (recorded on the last day of the quarter) depends on purchases that occurred on that very day for reasons unrelated to price manipulation, and that these stock purchases consequently push the price temporarily up.

To rule out this possibility, we relate end-of-quarter ownership to returns at the end of the next month. For example, we associate end-of-April returns with ownership measured at the end of March. Table 4, Panel A has the results from regressions in which ownership is lagged by one month relative to the returns. Following a similar logic, Panel B presents regressions in which hedge fund ownership is lagged by two months. The end-of-month jumps and the reversals on the next day are still significant for stocks with high hedge fund ownership, however the magnitude of the price swings is smaller than in Table 2. This change is easily explained by the fact that, in the last regressions, the ownership variable reflects stale information relative to the returns. In the course of the month between the measurement of ownership and returns, the portfolios of hedge funds may have changed considerably. It is therefore reassuring that we still find a significant end-of-month effect for stocks with high ownership, which tends to rule out the alternative explanation based on a mechanical link between portfolio reallocation and price impact. Importantly, this evidence is consistent with the idea that manipulation takes place on the monthly level, despite the fact that our ability to detect it on this frequency is limited due to the quarterly frequency of the holdings data.

Another concern is that the end-of-month price surge originates from the impact caused by hedge funds' attempts to scale up existing positions after positive flows of money. To rule out this possibility, we first identify hedge funds that are in the top tercile of the flow (in percentage 
of assets under management) for that quarter. Then, we create an indicator variable for stocks with above-median ownership by high-flow funds. We include this dummy in the original specification, which also has the above median ownership by all hedge funds. Finally, we add an interaction between the two ownership dummies. If the price impact is especially strong for stocks owned by high-flow funds, the interaction should be positive and significant. Table 4, Panel C, shows that in the last day of the quarter, the interaction is negative and statistically insignificant, while the coefficient on the above-median ownership by all hedge funds retains its significance. We conclude that high-flow funds are not behind the observed price surge. Further corroborating evidence is shown in Section 5 using a fund level analysis.

Another possibility is that hedge fund holdings are correlated with mutual fund holdings and therefore our results are a manifestation of the prior evidence by Carhart, Kaniel, Musto, and Reed (2002) about mutual funds manipulation of stock prices at the end of the quarter. To rule out this possibility, we add a control for stocks with above-median ownership by mutual funds (Table 4, Panel D). We also present specifications that only include mutual fund ownership. The results show that hedge fund ownership retains its significance and magnitude when controlling for mutual fund ownership. Consequently, hedge funds seem to add another layer of manipulation independent of what has already been found for mutual funds. ${ }^{13}$

Finally, there is a concern about the economic importance of the effect. In particular, while the increase in prices on the last day of the quarter is sizeable, it reverts on the following day. Thus, there is a possibility that the aggregate effect of hedge fund trades on monthly returns cancels out within the month, because the same stock might have low returns on the first day of the month and higher returns on the last day of the month. In other words, inflated returns at the last day of the month may come at the expense of a previous return decline at the beginning of the month due to downwards price pressure following stock manipulation in the previous month. To check this, we rerun the regressions from Table 1, controlling for the stock's returns on the first day of the month (Table 4, Panel E). The regression shows that the correlation between the returns on the first and the last day of the month is practically zero. Further, the correlation

\footnotetext{
${ }^{13}$ Incidentally, it is worth noting that the mutual fund ownership variable is associated with a negative end-of-month effect and a reversion on the first day of the month, although these effects are not statistically significant. This evidence would seem to suggests that the Carhart, Kaniel, Musto, and Reed (2002) effect is not present in this sample period.
} 
between the returns around the turn of the month and hedge fund ownership remains unchanged. We conclude that manipulation has a non-zero impact on monthly prices. This evidence speaks to the negative welfare implications of hedge funds' behavior as far as price informativeness is concerned.

\subsection{Intraday Returns}

To minimize the cost of inflating the stock price, hedge funds have an incentive to purchase stocks towards the end of the last trading day of the month. Inflating the price earlier in the day can be more expensive because the market has time to absorb the liquidity shocks, which may make further purchases necessary. The likelihood of this occurrence is minimized when the pumping-up occurs at the end of the day. To verify this conjecture, we compute stock returns for each thirty-minute interval between 9:30AM and 3PM and for each ten-minute interval between 3PM and 4PM. Then, we regress intra-day returns onto the above-median ownership dummy. Ownership is measured in the same month in order to maximize power. We expect to see the strongest effect of ownership on returns at the end of the day.

In Table 5, columns are labeled by the start time of the time interval; the results confirm

the validity of our conjecture. The price impact of hedge fund ownership becomes significantly different from zero in the interval that begins at 2PM. Consistent with our prediction, the price impact is the strongest in the last ten minutes of the trading day. The magnitude is large. Stocks with high hedge fund ownership have higher returns in the last twenty minutes of the day by roughly 10 basis points, which constitute about half of the daily increase (compare with the 18 bps in Table 2, Panel B).

Figure 1 summarizes the results. Figure 1a shows the cumulative return over the last day for stocks with above- and below-median hedge fund ownership. The figure shows the departure of returns of stocks with above-median hedge fund ownership in the last minutes of trade. Figure $1 \mathrm{~b}$ shows that on the first day of the month high hedge fund ownership stocks display lower returns, which start materializing right at the opening bell. In other words, as would reasonably be expected if the price changes are a pure liquidity effect, the reversal begins as soon as the market opens. 


\subsection{Which Stocks Are Prone to Manipulation?}

Next, we explore the characteristics of stocks that exhibit manipulation patterns. According to Hypothesis H2, stocks are more likely to be manipulated by hedge funds if they are relatively illiquid. To test this hypothesis, we regress daily returns around the turn of the month on an interaction of high hedge fund ownership indicator and high Amihud (2002) illiquidity indicator, as well as the main effects. We also control for size indicator and its interaction with hedge fund ownership indicator. The results in Table 6 are strongly consistent with the prediction of Hypothesis H2. Above-median illiquid stocks with above-median hedge fund ownership exhibit an abnormal return of 17 basis points relative to the abnormal return of all stocks; instead we find no effect of market capitalization and its interaction with hedge fund ownership.

\subsection{Hedge-Fund-Level Evidence of Quarter-End Manipulation}

Having provided evidence of manipulation at the stock level, we now turn to fund-level evidence by looking at the behavior of portfolios of stocks held by hedge funds at quarter end. For each hedge fund in the intersected dataset of $13 \mathrm{~F}$ and TASS, we calculate ret(last day), the returns of the fund's long equity portfolio, weighted by dollar holdings as reported in the fund's $13 \mathrm{~F}$ for that quarter end. Similarly, we define the returns of that same portfolio on the next day $($ ret(last day +1$))$ and previous day (ret(last day -1$))$ to the last trading day of the quarter.

A useful measure to identify manipulations is the "blip" of each fund's equity portfolio at the end of the quarter:

$$
\text { Blip }_{i, t}=\operatorname{ret}(\text { last day })_{i, t}-\operatorname{ret}(\text { last day }+1)_{i, t}
$$

Indeed, if a fund pushes its returns upwards at the end of a quarter, we expect a high ret(last day) followed by quick reversal, i.e. a low next-day returns, and thus a high blip. The blip can thus be used to identify potential manipulations. Since more volatile portfolios are more likely to experience a "blip" (for purely statistical reasons), a more accurate signal of manipulation is the volatility-adjusted blip:

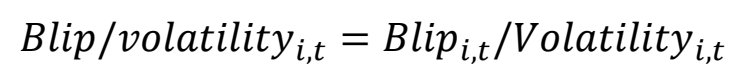


where Volatility $_{i, t}$ is the volatility of daily returns of fund i's portfolio estimated using daily returns of the quarter (and the quarter-end weights). This volatility-adjusted variable, which will be used to detect manipulation in the data, is distributed independently of volatility and, absent manipulations or other end-of-month anomalies, would be centered on zero. For the purpose of describing the variable we adjust returns by the market value-weighted portfolio. Using selfexplanatory notations, we call Adj ret(last day), Adj ret(last day + 1), Adj ret(last day - 1), and Adj Blip the market-adjusted variables.

As a starting point, we wish to confirm at the hedge fund level the anomaly we reported earlier at the stock level. In Table 7, we report descriptive statistics of these last four variables, calculated at the hedge fund level and averaged at the quarter level. In line with what one would expect if a fraction of the funds were engaging in monthly return upward manipulations on their long equity holdings, we find significantly positive adjusted returns at the end of the quarter followed by negative adjusted returns on the next quarter's first day. This abnormal adjusted blip is 52 bps on average and is not specific to December (the level is fairly constant among calendar months). The market-adjusted blips are significant for all of the 4 quarter-end months at the $2 \%$ level, clustering by date. The time-series of the average adjusted blip for each date appears to be positive for roughly $90 \%$ of the months of the sample. The $95 \%$ confidence interval for the average cross-sectional adjusted blip implied by this time-series is (36bps, 80bps).

Thus, we confirm at the fund level the anomaly documented at the stock level: that the portfolio of long equity holdings of hedge funds experience abnormal positive returns on average at the end of the month, followed by reversal on the next trading day. This is consistent with some hedge funds pumping up stock-prices at month-end. As we have done for the stock-level evidence, we will address other possible explanations, such as end-of-month rebalancing, in the section below.

\section{Characteristics of Manipulating Hedge Funds}

\subsection{Link with Incentives to Improve Returns}

In order to better understand the economics of stock manipulation, we try to identify the

hedge funds that exhibit the strongest manipulation patterns. Having described the blip measure 
for each fund-quarter, we now examine the fund-level characteristics related to high levels of blip. In Table 8, Columns (1) to (4), we perform panel regressions of the fund-level volatilityadjusted blip on a set of hedge funds characteristics. Our regressions include time fixed effects and standard errors are clustered at the fund level. We examine a number of explanatory variables: $\log (A U M)_{t}$ is the log of the assets under management (AUM) by the fund at the end of quarter $t, \log$ (Equity portfolio size $)_{t}$ is the log of the number of stocks held by the fund as a measure of diversification. Both variables are constructed using the funds' 13F filings. Using TASS data, we compute the percentage of flows out of lagged assets under management Fund flows / lag(AUM) (\%).

The results in Table 8 show that hedge funds with less diversified portfolios have higher blips, in line with the view that it is easier (less costly) for them to move their portfolio performance. In contrast, a highly diversified fund cannot generate a high impact on its returns by pushing a small number of stocks (Hypothesis H3a). Moreover, stocks owned by small hedge funds experience a larger blip (Hypothesis H3b).

To test Hypothesis H4, that links the incentives to manipulate with manipulation activity, we consider relative and absolute performance measures constructed using the TASS data. We call $I$ (Bad month) $)_{t}$ a dummy equal to one if the fund's performance at month $t$ is below $-2 \%$ (a threshold that corresponds to the bottom $15 \%$ of the distribution of monthly returns). To assess relative performance, we sort funds according to their year-to-date performance: YTD performance quintile $X_{t}$ is an ordinal discrete variable that distributes funds into 5 quintiles of year-to-date (YTD) performance as of the end of month $t$. We focus on YTD performance because it is a variable frequently used by investors to compare funds within the year. For instance, HSBC’s “Hedge Weekly” report provides “Top list” and "Bottom list” of funds according to their YTD performance.

The results in Table 8 confirm that hedge funds in the highest year-to-date performance quintile exhibit higher blips (Hypothesis H4a). This evidence is consistent with the crosssectional analysis of Carhart, Kaniel, Musto, and Reed (2002), which shows that mutual funds that engage in end-of-month price manipulations are past winners, potentially attempting to take advantage of the convexity of investment flow-performance. 
We also find that funds having a bad month (less than -2\%) are more likely to experience a blip, which can be explained by the concern that an overly negative return might tarnish the fund's track record (e.g., by increasing volatility). These results are economically sizable. Moving from the first to the fifth YTD performance quintile increases the expected volatilityadjusted blip by more than $7 \%$ of the variable's standard deviation, which is 1.4 . The magnitude of the effects can also be assessed in Table 8, Columns (5) to (8), where the dependent variable is ret(last day), the quarter's last-day return of the portfolio. These regressions show that funds that are experiencing a bad month or that are in the highest quintile of YTD performance have lastday returns that are around 15 bps higher than others.

To investigate further the link between incentives to manipulate and observed blips, we perform a detailed analysis of the characteristics of manipulating hedge funds. In Hypothesis H4b-d, we conjecture that manipulation is stronger for: (i) hedge funds with currently good relative performance, but with a poor past relative performance, (ii) young hedge funds, and (iii) early months in the calendar year.

As Table 9 shows, we find supportive evidence for all of these three varying hypotheses: hedge funds are more likely to experience a high blip when their YTD performance is high and they possess one of the characteristics that we explore. For the first case, Low reputation $t$ is a dummy equal to one if the YTD performance as of the last quarter (i.e., at month $t-3$ ) was in the bottom two quintiles (similar results hold in magnitude and significance by taking the first quintile only in the definition of Low reputation). Funds where Low reputation $=1$ were thus perceived, as of last quarter, to be substandard performers and were more likely to be included in poor-performer lists. If funds have an already-high current YTD return, they might benefit relatively more by climbing further on the ranking; for example, in order to make it to the top ten list. As for the second part of the hypothesis, Young $g_{t}$ is a dummy equal to one if the fund's age (measured from first date of inclusion in TASS) at month $t$ is below the sample's median, i.e., 7 years. In the third part of the hypothesis, which relates stronger manipulation early in the year, March is a dummy equal to one if the current calendar month is March. 


\subsection{Time-Series Evidence}

Next, we explore the time-series dimension of price manipulation. We first would like to verify that manipulation takes place over time and is not limited to a single episode in the decade being examined. Figure 2 presents a time series of the DGTW-adjusted equally-weighted average last-day-of-the-quarter returns over the sample period, where the stocks sample is split for high and low hedge fund holdings. The figure shows that in most quarters the end-of-month returns are higher for stocks with high hedge fund holdings.

To test the hypothesis that manipulation is stronger when stock market returns are low (Hypothesis H4e), we compute for each quarter-end month the average market-adjusted blips and test whether these aggregate blips are stronger when the market performs poorly. We find evidence that this is indeed the case (Table 10): the aggregate adjusted blips are significantly negatively correlated to monthly market performance. When the market is below its median, the average market-adjusted blip is higher by $44 \mathrm{bps}$, which is about two-thirds of a standard deviation move for this variable (the standard deviation is $67 \mathrm{bps}$ ). Since the sample is small, we present a scatter plot of the scaled blip, as a function of market returns in Figure 3. The figure shows that the result is not driven by outliers, but rather reflects a strong pattern in the data.

\subsection{Robustness and Alternative Explanations}

We now address a few potential concerns regarding the fund-level results' interpretation. First, the link between YTD performance and blips might come from a reverse causal relationship, in which the high blips are themselves the cause of the high YTD performance. This concern can be alleviated by including in the regression the fund's relative performance for the current month. We report this robustness check in Appendix Table 1: Current performance quintile $X_{t}$ is an ordered discrete variable that breaks funds in five quintiles according to month $t$ performance. The baseline results of Table 8 are unaffected by such a control. (They are also unchanged when the continuous relative performance variable is included.)

Another concern is that the results we report might be related to the price impact of trades that specifically occur at the end of the month rather than to intentional price manipulations. For instance, some funds with a high YTD performance might experience high inflows, leading to a 
large flow of stocks being bought at the quarter end. To alleviate this concern, we control for the percentage net flows in assets received by the fund at quarter end, Fund flows / $\operatorname{lag}(A U M)(\%)$. Following the literature standard (Chevalier and Ellison 1997, Sirri and Tufano 1998, Agarwal, Daniel, and Naik 2009, among others), we compute fund flows as the quarterly difference in AUM at quarter end minus the dollar return on the previous quarter AUM. Fund flows are then scaled by the lagged AUM. Columns (4) and (8) of Table 8 show that the results are unaffected by the inclusion of this control. The blip and last-day returns are actually not correlated with fund net flows (in unreported regressions, we also included forward and lagged measures of monthly net flows, with similar results), relaxing the concern that price-impact at month end is a driving force in these regressions.

\subsection{Persistence of Manipulation Behavior}

In the final part of the hedge fund-level analysis, we investigate whether manipulation patterns are persistent across hedge funds (Hypothesis H5). To this end, we regress the current quarterly blip on the lagged blip. Table 11 documents that blips are indeed significantly persistent from one quarter to the next: volatility-adjusted blips have an autocorrelation of around 0.11 . This subsists even when controlling for all the variables that have been seen as predictors of manipulation, as Column (3) indicates. This suggests that manipulating returns is a "habit" that tends to persist over time at the fund level.

\section{Feasibility Analysis}

We argue that the economic mechanism that drives the end-of-month returns is stock manipulation on the part of hedge funds. A necessary condition for this mechanism is that manipulation of stock prices is feasible with reasonable amount of capital. That is, we would like to see that the amount of money necessary to move prices by the observed magnitudes is accessible even to smaller hedge funds.

We verify that hedge funds can actually manipulate prices by examining the association between returns and signed volume. Therefore, the more immediate question is how much capital does it take to move the price of a stock by $1 \%$ ? We focus on the last seconds of trades on 
the last day of the month. An estimate of the sensitivity of prices to volume around this time is likely to provide an upper estimate for the amount of money needed for such trades, as stocks have generally high level of volume towards the end of the trading day.

We begin by splitting the universe of stocks into ten groups according to their Amihud (2002) illiquidity measure. Then we extract the last ten seconds of trade (15:59:50 to 15:59:59) in addition to the closing trades at 16:00:00 of the last day of the month for all the months from January 2000 to December 2009.

For each stock-second, we both compute returns and aggregate the dollar volume. In each Amihud illiquidity group, for each second, we run the following regression for all stock-seconds with non-zero dollar volume:

$$
\operatorname{ret}_{i, t}=a+b * \operatorname{sign}\left(\operatorname{ret}_{i, t}\right) * \$ v o l_{i, t}+e_{i, t}
$$

As ret $_{i, t}$ is expressed in percentage points, the inverse of the coefficient $b$ represents the dollar amount associated with a $1 \%$ movement in the price. We compute the inverse of the coefficient $b$ and present it in Figure 4 (with logarithmic scale).

The figure shows that during trading hours, changes of $1 \%$ in the prices of stocks with low liquidity (groups 6 to 10) are associated with dollar volumes lower than $\$ 0.5 \mathrm{~m}$. Changes in prices at the closing trade are associated with much larger amounts of money. At the closing (16:00:00), one needs $\$ 1 \mathrm{~m}$ to $\$ 10 \mathrm{~m}$ to move the price of low liquidity stocks by $1 \%$.

Consistent with Hypothesis H6 and with Cramer's own admission, we find that with a few millions, a trader can move the price of illiquid stocks by a percentage point or more. Thus, the manipulation of prices appears to be feasible with moderate resources.

\section{Conclusion}

In this paper, we use hedge fund holdings data to validate the conjecture that hedge funds manipulate stock prices before the close of trading at the end-of-month by buying some of their illiquid stock holdings before market close. This claim is supported by high end-of-month returns and a consequent reversal in the following day, as well as by intraday data, where we find that 
returns are especially high at the last minutes of trading. We document that manipulations are likely to take place in cases where the manipulation is likely to be most effective.

Our paper joins previous literature that discusses stock price manipulation before the bell for other investor populations. Carhart, Kaniel, Musto, and Reed (2002) find similar results for mutual funds, Ni, Pearson, and Poteshman (2005) for option traders, and Blocher, Engelberg, and Reed (2010) for short sellers. In a sense, our paper complements the latter study, since a large fraction of short selling volume is attributed to hedge funds (Boehmer, Ekkehart, and Jones 2008 and Goldman Sachs 2010).

The welfare costs induced by hedge funds' manipulations of monthly returns have the potential to be significant: the price effects are large and do not cancel out within the month. A major source of the economic costs of these manipulations stems from the fact that many contracts and performance measures in the economy are likely to rely on monthly returns. By jamming the signals on which their own performance is evaluated, hedge funds add noise to a widely used signal, thus exercising a negative externality on the rest of the economy. 


\section{References}

Agarwal, Vikas, Naveen D. Daniel, and Narayan Y. Naik, 2009, Do Hedge Funds Manage Their Reported Returns?, Working Paper, Georgia State University.

Agarwal, Vikas, Vyacheslav Fos, and Wei Jiang, 2010, Inferring Reporting Biases in Hedge Fund Databases from Hedge Fund Equity Holdings, Working Paper, Columbia University.

Aggarwal, Rajesh K., and Guojun Wu, 2006, Stock Market Manipulations, Journal of Business 79(4), 1915-1953.

Allen, Franklin, Lubomir Litov, and Jianping Mei, 2006, Large Investors, Price Manipulation, and Limits to Arbitrage: An Anatomy of Market Corners, Review of Finance 10(4), 645-693.

Amihud, Yakov, 2002, Illiquidity and Stock Returns: Cross-Section and Time-Series Effects, Journal of Financial Markets 5, 31-56.

Asness, Cliff, Robert Krail, and John Liew, 2001, Do Hedge Funds Hedge?, Working Paper, AQR Capital.

Ben-David, Itzhak, Francesco Franzoni, and Rabih Moussawi, 2010, Hedge Fund Stock Trading during the Financial Crisis of 2007-2008, Working Paper, The Ohio State University, University of Lugano, and University of Pennsylvania.

Blocher, Jesse, Joseph Engelberg, and Adam V. Reed, 2010, The Long-Short Wars: Evidence of End-ofYear Manipulation by Short Sellers, Working Paper, University of North Carolina.

Boehmer, Ekkehart, and Charles M. Jones, 2008, Which Shorts are Informed?, Journal of Finance 63(2), 491-527.

Bollen, Nicolas P. B., and Veronika K. Pool, 2008, Conditional Return Smoothing in the Hedge Fund Industry, Journal of Financial and Quantitative Analysis 43(2), 267-298.

Bollen, Nicolas P. B., and Veronika K. Pool, 2009, Do Hedge Funds Misreport Returns? Evidence from Pooled Distributions, Journal of Finance 64(5), 2257-2288.

Brunnermeier, Markus K., and Stefan Nagel, 2004, Hedge Funds and the Technology Bubble, Journal of Finance 59(5), 2013-2040.

Carhart, Mark, Ron Kaniel, and Adam Reed, 2002, Leaning for the Tape: Evidence of Gaming Behavior in Equity Mutual Funds, Journal of Finance 57(2), 661-693.

Campbell, John Y., Tarun Ramadorai, and Allie Schwartz, 2009, Caught on Tape: Institutional Trading, Stock Returns, and Earnings Announcements, Journal of Finance 92(1), 66-91.

Cici, Gjergji, Alexander Kempt, and Alexander Puetz, 2010, Caught in the Act: How Hedge Funds Manipulate their Equity Positions, Working Paper, William and Mary College.

Comerton-Forde, Carole, and Talis J. Putnins, The Prevalence and Underpinnings of Closing Price Manipulation, Working Paper, University of Sydney and Stockholm School of Economics.

Daniel, Kent, Mark Grinblatt, Sheridan Titman, and Ross Wermers, 1997, Measuring Mutual Fund Performance with Characteristic Based Benchmarks, Journal of Finance 52, 1035-1058.

Getmansky Mila, Andy W. Lo, and Igor Makarov, 2004, An Econometric Model of Serial Correlation and Illiquidity in Hedge Fund Returns, Journal of Financial Economics 74 (3), 529-610.

Holmström, Bengt, 1999, Managerial Incentive Problems: A Dynamic Perspective, Review of Economic Studies 66, 169-182. 
Holmström, Bengt, and Paul Milgrom, 1991, Multitask Principal-Agent Analyses: Incentive Contracts, Asset Ownership, and Job Design, Journal of Law, Economics, \& Organization 7, 24-52.

Ippolito, Roger A., 1992, Consumer Reaction to Measures of Poor Quality: Evidence from the Mutual Fund Industry, Journal of Law and Economics 35, 45-70.

Lemke, Thomas P., and Gerald T. Lins, 1987, Disclosure of Equity Holdings by Institutional Investment Managers: An Analysis of Section 13(f) of the Securities Exchange Act of 1934, Business Lawyer (ABA) 43, 93-119.

Ni, Sophie, Neil Pearson, and Allen M. Poteshman, 2005, Stock Price Clustering on Option Expiration Dates, Journal of Financial Economics 78, 49-87.

Sirri, Erik R., and Peter Tufano, 1998, Costly Search and Mutual Fund Flows, Journal of Finance 53, 1589-1622.

Wermers, Russ, 2000, Mutual Fund Performance: An Empirical Decomposition into Stock-Picking Talent, Style, Transactions Costs, and Expenses, Journal of Finance 55, 1655-1695. 


\section{Table 1. Summary Statistics}

The table reports summary statistics. Panel A presents summary statistics of stock-day observations of the last day of the month (summary statistics of other days around the turn of the month are very similar). Panel B presents summary statistics at the hedge-fund-quarter level. The sample period is 2000Q1 to 2009Q4.

\section{Panel A: Stock-Day Level Summary Statistics}

\begin{tabular}{|c|c|c|c|c|c|c|c|c|}
\hline & $\mathrm{N}$ & Mean & Std Dev & Min & p25 & p50 & p75 & Max \\
\hline Return last day (\%, DGTW adjusted) & 128841 & 0.021 & 3.772 & -74.251 & -1.361 & -0.067 & 1.260 & 14.469 \\
\hline Return first day (\%, DGTW adjusted) & 128868 & -0.126 & 3.728 & -81.250 & -1.539 & -0.072 & 1.398 & 14.469 \\
\hline Return second day (\%, DGTW adjusted) & 128800 & -0.059 & 3.612 & -94.788 & -1.451 & -0.070 & 1.358 & 14.469 \\
\hline Return second-to-last day (\%, DGTW adjusted) & 128844 & -0.019 & 3.484 & -71.286 & -1.288 & -0.060 & 1.224 & 14.469 \\
\hline HF ownership (\%) & 128910 & 2.615 & 3.803 & 0.000 & 0.440 & 1.258 & 3.246 & 100.000 \\
\hline Mutual Fund ownership (\%) & 128910 & 13.637 & 9.481 & 0.000 & 6.095 & 12.303 & 19.656 & 100.000 \\
\hline Ownership by high-inflow funds (\%) & 128910 & 0.640 & 1.829 & 0.000 & 0.000 & 0.043 & 0.456 & 100.000 \\
\hline Amihud & 128910 & 0.310 & 0.974 & 0.000 & 0.001 & 0.008 & 0.072 & 5.000 \\
\hline Market capitalization & 125861 & $4.08 \mathrm{E}+09$ & $1.77 \mathrm{E}+10$ & $-1.03 \mathrm{E}+09$ & $1.60 \mathrm{E}+08$ & $5.40 \mathrm{E}+08$ & $1.89 \mathrm{E}+09$ & $5.71 \mathrm{E}+11$ \\
\hline
\end{tabular}

\section{Panel B: Hedge Fund-Quarter Level Summary Statistics}

\begin{tabular}{|c|c|c|c|c|c|c|c|c|}
\hline & $\mathrm{N}$ & Mean & Std Dev & Min & p25 & p50 & p75 & Max \\
\hline$\overline{\text { Adj ret(last day) }}$ & 6649 & 0.368 & 1.558 & -8.527 & -0.400 & 0.063 & 0.725 & 14.743 \\
\hline Adj ret(last day +1$)$ & 6649 & 0.002 & 0.020 & -0.138 & -0.007 & 0.003 & 0.012 & 0.118 \\
\hline Adj ret(last day - 1) & 6649 & 0.001 & 0.020 & -0.167 & -0.002 & 0.002 & 0.010 & 0.091 \\
\hline Adj Blip = Adj ret(last day + 1) - Adj ret(last day) & 6649 & 0.008 & 0.044 & -0.553 & -0.006 & 0.008 & 0.022 & 0.746 \\
\hline $\log (A U M)$ & 6649 & 5.439 & 1.742 & -5.163 & 4.498 & 5.490 & 6.512 & 10.915 \\
\hline $\log$ (\# Stocks in equity portfolio) & 6649 & 3.885 & 1.281 & 0.000 & 3.219 & 3.892 & 4.575 & 7.839 \\
\hline Fund flows / lag(AUM) (\%) & 5741 & 0.010 & 0.041 & -0.311 & -0.003 & 0.003 & 0.019 & 0.237 \\
\hline
\end{tabular}




\section{Table 2. End-of-Quarter Returns for High HF Ownership Stocks}

The table reports results from OLS regressions in which the dependent variable is the daily percentage return adjusted using the Daniel, Grinblatt, Titman, and Wermers (1997) (DGTW) approach. Four specifications are reported for which the dependent variables are the stock return in the second-to-last, last, next-to-last, and secondafter-the-last days of the quarter, respectively. In Panel A, the explanatory variable is an indicator for stocks' hedge fund ownership (by quartile) for that same quarter. In Panel B, the explanatory variable is an indicator for whether stocks' hedge fund ownership is above the median for that same quarter. $t$-statistics are reported in parentheses. Standard errors are clustered by date. ${ }^{* * *},{ }^{* *}$, and ${ }^{*}$ denote statistical significance at the $1 \%, 5 \%$, and $10 \%$ levels, respectively. The sample period is 2000Q1 to 2009Q4.

\section{Panel A: Regression on Hedge Fund Ownership Quartiles}

Dep. variable: DGTW adjusted return

\begin{tabular}{lcccc}
\multirow{2}{*}{ Day of the month: } & \multicolumn{1}{c}{ last day - } & last day & last day +1 & last day +2 \\
\cline { 2 - 5 } & $(1)$ & $(2)$ & $(3)$ & $(4)$ \\
\hline HF ownership Q2 & -0.012 & 0.044 & -0.018 & -0.019 \\
HF ownership Q3 & $(-0.425)$ & $(1.350)$ & $(-0.626)$ & $(-0.749)$ \\
& 0.043 & $0.119^{* *}$ & $-0.088^{*}$ & -0.018 \\
HF ownership Q4 & $(1.506)$ & $(2.687)$ & $(-1.984)$ & $(-0.321)$ \\
& 0.003 & $0.299^{* * *}$ & $-0.245^{* * *}$ & -0.097 \\
Constant & $(0.069)$ & $(6.802)$ & $(-4.175)$ & $(-1.606)$ \\
& & & & \\
Observations & -0.028 & $-0.092^{* * *}$ & -0.033 & -0.016 \\
Adjusted R & $(-1.379)$ & $(-2.989)$ & $(-1.218)$ & $(-0.617)$ \\
\hline
\end{tabular}

\section{Panel B: Regression on Hedge Fund Ownership Halves}

\begin{tabular}{lcccc} 
& \multicolumn{4}{c}{ Dependent variable: DGTW adjusted return } \\
\cline { 2 - 5 } \multicolumn{1}{c}{ Day of the month: } & last day -1 & last day & last day +1 & last day +2 \\
\cline { 2 - 5 } & $(1)$ & $(2)$ & $(3)$ & $(4)$ \\
\hline HF ownership (top half) & 0.034 & $0.184^{* * *}$ & $-0.140^{* * *}$ & -0.046 \\
& $(1.185)$ & $(6.398)$ & $(-3.440)$ & $(-0.993)$ \\
Constant & & & & \\
& $-0.039^{* *}$ & $-0.065^{* *}$ & $-0.051^{* *}$ & -0.036 \\
& $(-2.684)$ & $(-2.237)$ & $(-2.059)$ & $(-1.491)$ \\
Observations & & & & \\
Adjusted $\mathrm{R}^{2}$ & 126630 & 126627 & 122326 & 122324 \\
\hline
\end{tabular}




\section{Table 3. End-of-Quarter Returns for High HF Ownership Stocks, by Quarter}

The table reports results from OLS regressions in which the dependent variable is the daily percentage return adjusted using the Daniel, Grinblatt, Titman, and Wermers (1997) approach. For each quarter, the dependent variable is the stock return on the last day of the quarter and on the first day of the next quarter. The explanatory variable is an indicator for stocks for which hedge fund ownership is above the median for that quarter. $t$-statistics are reported in parentheses. Standard errors are clustered by date. ${ }^{* * *},{ }^{* *}$, and ${ }^{*}$ denote statistical significance at the $1 \%, 5 \%$, and 10\% levels, respectively. The sample period is 2000Q1 to 2009Q4.

Dependent variable: DGTW adjusted return

\begin{tabular}{|c|c|c|c|c|c|c|c|c|}
\hline \multirow{4}{*}{$\begin{array}{r}\text { Quarter: } \\
\text { Day of the month: }\end{array}$} & \multirow{2}{*}{\multicolumn{2}{|c|}{ Q1 }} & \multirow{2}{*}{\multicolumn{2}{|c|}{ Q2 }} & \multirow{2}{*}{\multicolumn{2}{|c|}{ Q3 }} & \multirow{2}{*}{\multicolumn{2}{|c|}{ Q4 }} \\
\hline & & & & & & & & \\
\hline & last day & last day +1 & last day & last day +1 & last day & last day +1 & last day & last day +1 \\
\hline & $(1)$ & $(2)$ & (3) & (4) & (5) & (6) & (7) & (8) \\
\hline \multirow[t]{2}{*}{ HF ownership (top half) } & 0.141 & $-0.155^{*}$ & $0.185^{* *}$ & $-0.280 * *$ & $0.348^{* * *}$ & -0.133 & $0.407^{* * *}$ & $-0.207 * *$ \\
\hline & $(1.808)$ & $(-1.871)$ & (3.004) & $(-2.395)$ & $(4.673)$ & $(-1.513)$ & $(5.468)$ & $(-2.766)$ \\
\hline \multirow[t]{2}{*}{ Constant } & 0.017 & $-0.141 *$ & 0.019 & -0.067 & -0.068 & $-0.125^{* *}$ & -0.076 & 0.015 \\
\hline & $(0.498)$ & $(-2.148)$ & $(0.414)$ & $(-1.705)$ & $(-0.768)$ & $(-2.415)$ & $(-1.030)$ & $(0.318)$ \\
\hline Observations & 32366 & 32172 & 31838 & 31657 & 31289 & 31062 & 31134 & 27435 \\
\hline Adjusted $\mathrm{R}^{2}$ & 0.000 & 0.000 & 0.000 & 0.001 & 0.001 & 0.000 & 0.002 & 0.000 \\
\hline
\end{tabular}




\section{Table 4. Robustness of Daily Return Analysis}

The table reports results from OLS regressions in which the dependent variable is the daily percentage return adjusted using the Daniel, Grinblatt, Titman, and Wermers (1997) approach. Four specifications are reported in which the dependent variables are the stock return in the second-to-last, last, next-to-last, and second-after-the-last days of the month for January, April, July, and October end-of-months. The explanatory variable in Panels A and B are a one and two, respectively, quarter-lagged indicator for stocks for which hedge fund ownership is above the median at the end of the previous quarter. The explanatory variables in Panel $\mathrm{C}$ is an indicator for stocks for which hedge fund ownership is above the median at the end of the previous quarter, and the DGTW-adjusted return of the first day of the month. In Panel D, the explanatory variables include: an indicator for stocks for which hedge fund ownership is above the median for that same quarter, an indicator for stocks with above median ownership by highflow hedge funds (which are in the top tercile of the flow distribution in the quarter), and the interaction between these two variables. In Panel E, the explanatory variables are two indicators for stocks for which mutual and hedge fund ownership are above the median for that same quarter, respectively. $t$-statistics are reported in parentheses. Standard errors are clustered by date. ${ }^{* * *},{ }^{* *}$, and ${ }^{*}$ denote statistical significance at the $1 \%, 5 \%$, and $10 \%$ levels, respectively. The sample period is 2000Q1 to 2009Q4.

\section{Panel A: Regressions of Returns around the Turn of the Month on One-Month-Lagged Hedge Fund Ownership}

Dependent variable: DGTW adjusted return

\begin{tabular}{|c|c|c|c|c|}
\hline Day of the month: & last day - 1 & last day & $\frac{\text { last day }+1}{(3)}$ & $\frac{\text { last day }+2}{(4)}$ \\
\hline \multirow[t]{2}{*}{ lag(HF ownership (top half)) } & -0.014 & $0.065 * *$ & $-0.077 * *$ & -0.042 \\
\hline & $(-0.318)$ & (2.113) & $(-2.441)$ & $(-1.392)$ \\
\hline \multirow[t]{2}{*}{ Constant } & 0.006 & 0.031 & -0.000 & 0.009 \\
\hline & $(0.363)$ & $(1.668)$ & $(-0.019)$ & $(0.499)$ \\
\hline Observations & 130664 & 130108 & 130005 & 129975 \\
\hline Adjusted $\mathrm{R}^{2}$ & -0.000 & 0.000 & 0.000 & 0.000 \\
\hline
\end{tabular}

\section{Panel B: Regressions of Returns around the Turn of the Month on Two-Month-Lagged Hedge Fund Ownership}

Dependent variable: DGTW adjusted return

\begin{tabular}{|c|c|c|c|c|}
\hline \multirow[t]{2}{*}{ Day of the month: } & last day - 1 & last day & last day +1 & last day +2 \\
\hline & $(1)$ & (2) & (3) & (4) \\
\hline \multirow[t]{2}{*}{ lag2(HF ownership (top half)) } & -0.010 & $0.116^{* * *}$ & 0.036 & -0.031 \\
\hline & $(-0.338)$ & (3.793) & $(0.853)$ & $(-0.766)$ \\
\hline \multirow[t]{2}{*}{ Constant } & 0.015 & 0.024 & 0.012 & 0.006 \\
\hline & $(0.721)$ & $(1.622)$ & $(0.580)$ & $(0.352)$ \\
\hline Observations & 129970 & 129341 & 129249 & 129209 \\
\hline Adjusted $\mathrm{R}^{2}$ & -0.000 & 0.000 & 0.000 & 0.000 \\
\hline
\end{tabular}


Table 4. Robustness of Daily Return Analysis (Cont.)

\section{Panel C: Controlling for Stocks Owned by Hedge Funds with High Flows}

\begin{tabular}{lcccc}
\multirow{2}{*}{ Day of the month: } & \multicolumn{4}{c}{ Dependent variable: DGTW adjusted return } \\
\cline { 2 - 5 } & last day - 1 & last day & last day +1 & last day +2 \\
\cline { 2 - 5 } & $(1)$ & $(2)$ & $(3)$ & $(4)$ \\
\hline HF ownership (top half) & 0.033 & $0.185^{* * *}$ & $-0.140^{* * *}$ & -0.048 \\
First-day-of-the-month DGTW return & $(1.164)$ & $(6.432)$ & $(-3.436)$ & $(-1.050)$ \\
& 0.010 & -0.011 & 0.013 & -0.012 \\
Constant & $(0.738)$ & $(-1.055)$ & $(1.125)$ & $(-0.685)$ \\
& $-0.039^{* *}$ & $-0.065^{* *}$ & $-0.052^{* *}$ & -0.036 \\
Observations & $(-2.642)$ & $(-2.236)$ & $(-2.080)$ & $(-1.489)$ \\
Adjusted R ${ }^{2}$ & & & & \\
\hline
\end{tabular}

\section{Panel D: Controlling for Mutual Fund Ownership}

\begin{tabular}{lccccccccc} 
& \multicolumn{7}{c}{ Dependent variable: DGTW adjusted return } \\
\cline { 2 - 9 } Day of the month: & last day -1 & last day & last day +1 last day +2 & last day -1 & last day & \multicolumn{1}{c}{ last day +1 last day +2} \\
\cline { 2 - 9 } & $(1)$ & $(2)$ & $(3)$ & $(4)$ & $(5)$ & $(6)$ & $(7)$ & $(8)$ \\
\hline HF ownership (top half) & & & & & 0.034 & $0.185^{* * *}$ & $-0.146^{* * *}$ & -0.046 \\
& & & & & $(1.156)$ & $(6.401)$ & $(-3.390)$ & $(-1.012)$ \\
MF ownership (top half) & 0.106 & -0.103 & 0.101 & -0.016 & 0.106 & -0.104 & 0.102 & -0.016 \\
& $(1.620)$ & $(-1.583)$ & $(1.255)$ & $(-0.172)$ & $(1.615)$ & $(-1.601)$ & $(1.271)$ & $(-0.167)$ \\
Constant & -0.091 & 0.095 & $-0.192^{* *}$ & -0.050 & $-0.108^{*}$ & 0.005 & $-0.122^{*}$ & -0.027 \\
& $(-1.490)$ & $(1.614)$ & $(-2.524)$ & $(-0.568)$ & $(-1.980)$ & $(0.085)$ & $(-1.793)$ & $(-0.360)$ \\
& & & & & & & & \\
Observations & 126630 & 126627 & 124066 & 124064 & 126630 & 126627 & 124066 & 124064 \\
Adjusted R $\mathrm{R}^{2}$ & 0.000 & 0.000 & 0.000 & -0.000 & 0.000 & 0.001 & 0.001 & 0.000 \\
\hline
\end{tabular}

Panel E: Regressions of Returns around the Turn of the Month on Hedge Fund Ownership, Controlling for Returns of the First Day of the Month

Dependent variable: DGTW adjusted return

\begin{tabular}{lcccc}
\multirow{2}{*}{ Day of the month: } & \multicolumn{3}{c}{ last day -1} & \multicolumn{3}{c}{ last day } & \multicolumn{2}{l}{ last day +1} & last day +2 \\
\cline { 2 - 5 } & $(1)$ & $(2)$ & $(3)$ & $(4)$ \\
\hline HF ownership (top half) & 0.083 & $0.244^{* * *}$ & $-0.207^{* * *}$ & -0.110 \\
& $(1.289)$ & $(4.715)$ & $(-3.411)$ & $(-1.151)$ \\
Ownership by high-inflow funds (top half) & $0.072^{*}$ & 0.058 & 0.056 & -0.017 \\
& $(1.814)$ & $(1.386)$ & $(1.305)$ & $(-0.450)$ \\
HF ownership x ownership by high-inflow funds & -0.095 & $-0.102^{*}$ & $0.101^{*}$ & 0.109 \\
& $(-1.364)$ & $(-1.796)$ & $(1.708)$ & $(1.145)$ \\
Constant & $-0.073^{* *}$ & $-0.101^{* *}$ & $-0.088^{* *}$ & -0.028 \\
& $(-2.230)$ & $(-2.116)$ & $(-2.125)$ & $(-0.756)$ \\
Observations & & & & \\
Adjusted $\mathrm{R}^{2}$ & 128871 & 128868 & 128349 & 128347 \\
\hline
\end{tabular}




\section{Table 5. Intraday Returns}

The table reports results from OLS regressions in which the dependent variable is the percentage return in the relevant time interval for which we report the beginning time. We consider both thirty minute and ten minute intervals. We report results for four different days: the second-to-last, last, next-to-last, and second-after-the-last days of the quarter, respectively. The explanatory variable is an indicator for stocks for which hedge fund ownership is above the median for that same quarter. Adjusted $\mathrm{R}^{2}$ is zero in all regressions. $t$-statistics are reported in parentheses. Standard errors are clustered by date. ${ }^{* * *},{ }^{* *}$, and ${ }^{*}$ denote statistical significance at the $1 \%, 5 \%$, and $10 \%$ levels, respectively. The sample period is 2000Q1 to 2009Q4.

\begin{tabular}{|c|c|c|c|c|c|c|c|c|c|c|c|}
\hline \multirow[b]{3}{*}{ Sample: Last Day -1 $(\mathrm{N}=139291)$} & \multicolumn{5}{|c|}{ Stock return (half an hour intervals) } & \multicolumn{6}{|c|}{ Stock return (10 minute intervals) } \\
\hline & 9:30 & 11:30 & 13:30 & 14:00 & $14: 30$ & $15: 00$ & $15: 10$ & $15: 20$ & $15: 30$ & $15: 40$ & $15: 50$ \\
\hline & $(1)$ & $(2)$ & (3) & (4) & $(5)$ & $(6)$ & $(7)$ & $(8)$ & (9) & $(10)$ & $(11)$ \\
\hline HF ownership (top half) & 0.020 & -0.001 & 0.018 & -0.003 & 0.001 & 0.002 & 0.004 & -0.001 & 0.002 & 0.008 & $0.016 *$ \\
\hline & $(0.970)$ & $(-0.138)$ & $(1.394)$ & $(-0.341)$ & $(0.171)$ & $(0.436)$ & $(0.589)$ & $(-0.116)$ & $(0.279)$ & $(0.945)$ & (1.919) \\
\hline Intercept & $\begin{array}{c}-0.160 \\
(-1.106)\end{array}$ & $\begin{array}{c}-0.001 \\
(-0.041)\end{array}$ & $\begin{array}{c}-0.080 \\
(-1515)\end{array}$ & $\begin{array}{c}0.013 \\
0.346)\end{array}$ & $\begin{array}{c}0.010 \\
(0.305)\end{array}$ & $\begin{array}{c}-0.007 \\
(-0.375)\end{array}$ & $\begin{array}{l}-0.036^{*} \\
(-1756)\end{array}$ & $\begin{array}{c}-0.013 \\
(-0.506)\end{array}$ & $\begin{array}{c}0.018 \\
(1052)\end{array}$ & 0.039* & $0.082 * *$ \\
\hline
\end{tabular}

\begin{tabular}{lcccccccccccc} 
Sample: Last Day $(\mathrm{N}=139536)$ & \\
\hline HF ownership (top half) & $0.031^{*}$ & 0.009 & 0.009 & $0.014^{*}$ & 0.010 & $0.013^{* * *}$ & $0.010^{*}$ & 0.008 & 0.004 & $0.024^{* *}$ & $0.073^{* * *}$ \\
& $(1.699)$ & $(1.123)$ & $(1.315)$ & $(1.866)$ & $(1.321)$ & $(2.950)$ & $(1.824)$ & $(1.502)$ & $(0.537)$ & $(2.703)$ & $(8.172)$ \\
Intercept & -0.072 & 0.030 & $0.055^{* *}$ & 0.030 & 0.044 & $-0.044^{*}$ & -0.017 & -0.017 & -0.037 & -0.020 & -0.020 \\
& $(-0.802)$ & $(1.198)$ & $(2.125)$ & $(1.045)$ & $(1.469)$ & $(-1.975)$ & $(-0.736)$ & $(-0.774)$ & $(-1.248)$ & $(-0.739)$ & $(-0.804)$ \\
\hline
\end{tabular}

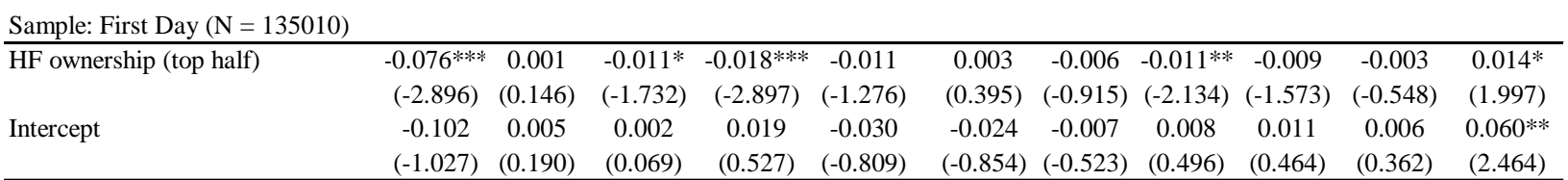

\begin{tabular}{|c|c|c|c|c|c|c|c|c|c|c|c|}
\hline HF ownership (top half) & $\begin{array}{c}-0.022 \\
(-0.690)\end{array}$ & $\begin{array}{c}-0.013 \\
(-0.899)\end{array}$ & $\begin{array}{c}0.022 \\
(1.241)\end{array}$ & $\begin{array}{c}0.009 \\
(0.775)\end{array}$ & $\begin{array}{c}-0.010 \\
(-0.834)\end{array}$ & $\begin{array}{c}0.005 \\
(0.967)\end{array}$ & $\begin{array}{c}0.004 \\
(1.028)\end{array}$ & $\begin{array}{c}0.001 \\
(0.084)\end{array}$ & $\begin{array}{c}0.007 \\
(1.171)\end{array}$ & $\begin{array}{c}0.001 \\
(0.229)\end{array}$ & $\begin{array}{l}0.017 * * \\
(2.265)\end{array}$ \\
\hline Intercept & $\begin{array}{c}-0.167 \\
(-1.178)\end{array}$ & $\begin{array}{c}-0.040 \\
(-0.675)\end{array}$ & $\begin{array}{l}0.069 * \\
(1.962)\end{array}$ & $\begin{array}{c}-0.035 \\
(-0.768)\end{array}$ & $\begin{array}{c}-0.047 \\
(-1.623)\end{array}$ & $\begin{array}{c}-0.018 \\
(-0.945)\end{array}$ & $\begin{array}{c}-0.021 \\
(-0.982)\end{array}$ & $\begin{array}{c}-0.023 \\
(-0.857)\end{array}$ & $\begin{array}{c}-0.007 \\
(-0.299)\end{array}$ & $\begin{array}{c}-0.013 \\
(-0.665)\end{array}$ & $\begin{array}{c}0.036 \\
(1.602)\end{array}$ \\
\hline
\end{tabular}




\section{Table 6. Stock Level Incentives to Manipulate}

The table reports results from OLS regressions in which the dependent variable is the daily percentage return adjusted using the Daniel, Grinblatt, Titman, and Wermers (1997) approach. The dependent variables are the stock return in the second-to-last, last, next-to-last, and second-after-the-last days of the quarter, respectively. The explanatory variables are indicators for above-median hedge fund ownership, above-median market capitalization, above-median (2002) price impact measure, and their interactions. $t$-statistics are reported in parentheses. Standard errors are clustered by date. ${ }^{* * *},{ }^{* *}$, and ${ }^{*}$ denote statistical significance at the $1 \%, 5 \%$, and $10 \%$ levels, respectively. The sample period is 2000Q1 to 2009Q4.

Dependent variable: DGTW adjusted return

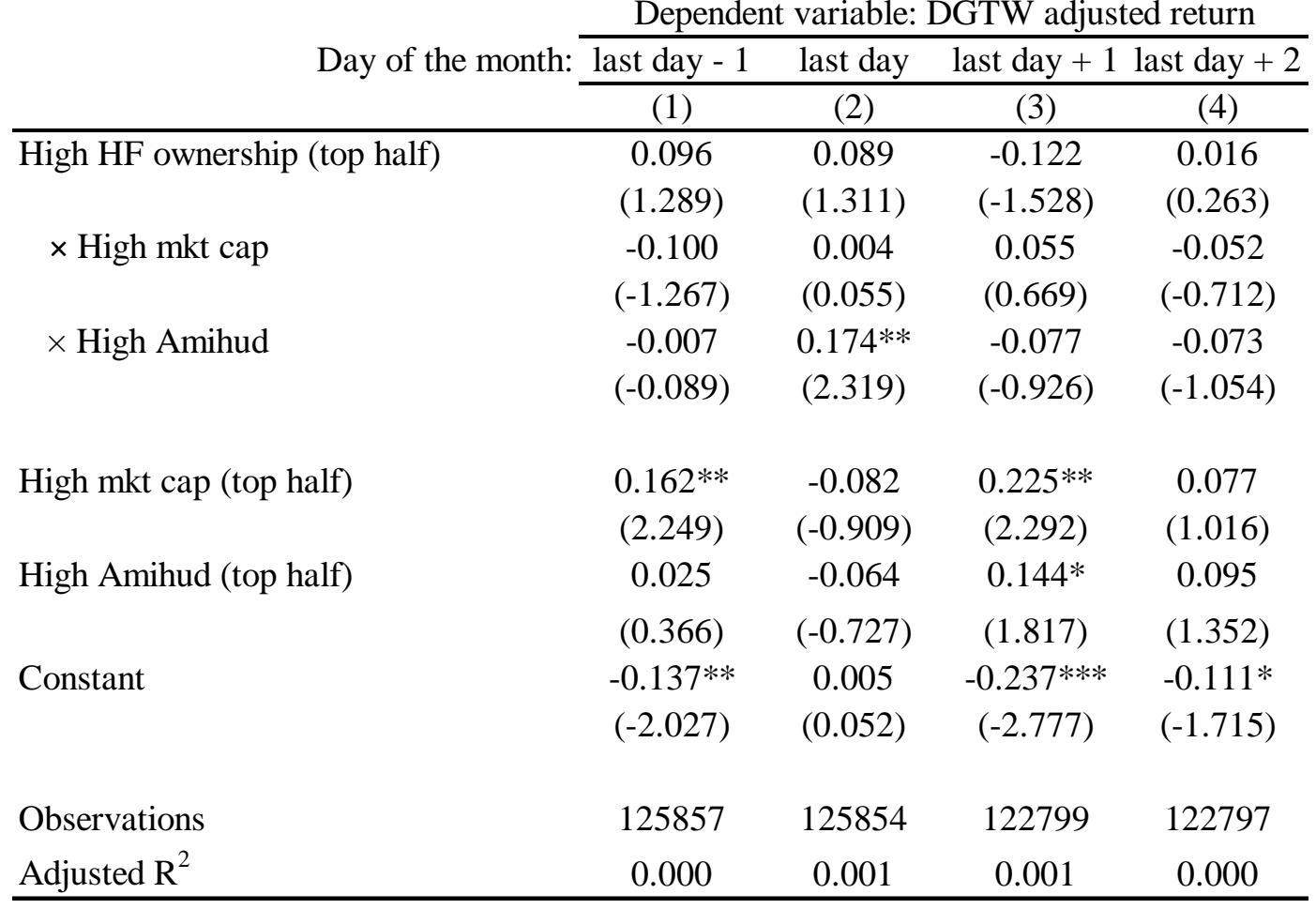




\section{Table 7. Fund-Level Evidence of Abnormal Month-end Returns}

The table reports the average market-adjusted daily returns for equity portfolios held at quarter's end by hedge funds. Adj ret (last day) is the market-adjusted return of this portfolio on the last trading day of the quarter and Adj ret (last day - 1) (Adj ret (last day +1$)$ ) are the returns of the same portfolio on the next (previous) trading day Adj Blip is defined at the fund level as the difference between Adj ret (last day) and Adj ret (last day +1 ). The universe is all TASS hedge funds for 2000Q1 to 2009Q4, for which the 13F is known.

\begin{tabular}{lccccc} 
& \multicolumn{5}{c}{ Average market-adjusted returns } \\
\cline { 2 - 6 } & All & March & June & September & December \\
\cline { 2 - 6 } & $(1)$ & $(2)$ & $(3)$ & $(4)$ & $(5)$ \\
\hline Adj ret(last day - 1) & $0.13 \%$ & $0.06 \%$ & $0.15 \%$ & $0.14 \%$ & $0.11 \%$ \\
Adj ret(last day) & $0.31 \%$ & $0.30 \%$ & $0.26 \%$ & $0.20 \%$ & $0.31 \%$ \\
Adj ret(last day + 1) & $-0.20 \%$ & $-0.16 \%$ & $-0.22 \%$ & $-0.27 \%$ & $-0.12 \%$ \\
\hline Adj Blip = Adj ret(last day + 1) - Adj ret(last day) & $0.52 \%$ & $0.46 \%$ & $0.48 \%$ & $0.47 \%$ & $0.46 \%$ \\
\hline
\end{tabular}




\section{Table 8. Which Hedge Funds Manipulate Prices? Volatility-Adjusted Blips}

The table reports fund-level OLS regressions of volatility-adjusted quarter-end "blips" of hedge fund portfolios. Specifically, the dependent variable in Columns (1) to (4), Blip/Volatility, is defined for each fund-quarter as the difference between ret(last day) and ret(last day +1 ) divided by the daily volatility of the portfolio over the quarter. The dependent variable in Panel B is ret(last day of quarter), which is the quarter-end daily returns of their equity portfolio (based on holdings reported in 13Fs). ret(last day) is the return of this portfolio on the last trading day of the quarter and ret(last day +1$)$ is the return of the same portfolio on the next trading day. The determinants are: the $\log$ of dollar long equity holdings reported in the $13 \mathrm{~F}(\log (A U M))$, the log of the number of stocks reported in the 13F (log(Equity portfolio size)), asset net flows as a percentage of lagged AUM (Fund flows / lag(AUM) (\%)), a dummy variable (I(Bad month)) for whether the current month's performance is below -2\%, and YTD performance (as of quarter's end) by quintiles (YTD performance quintile $X$ ). The universe is all TASS hedge funds for $2000 \mathrm{Q} 1$ to 2009Q4, for which the $13 \mathrm{~F}$ is known. T-statistics are reported in parentheses. ${ }^{* * *},{ }^{* *}$, and ${ }^{*}$ denote statistical significance at the $1 \%, 5 \%$, and $10 \%$ levels, respectively. Standard errors are clustered at the fund level and timefixed effects are included.

\begin{tabular}{|c|c|c|c|c|c|c|c|c|}
\hline \multirow[t]{2}{*}{ Dependent Variable: } & \multicolumn{4}{|c|}{ Blip/volatility } & \multicolumn{4}{|c|}{ ret(last day of quarter) } \\
\hline & (1) & (2) & (3) & (4) & (5) & (6) & (7) & (8) \\
\hline \multirow[t]{2}{*}{$\overline{l o g}(\mathrm{AUM})$} & -0.001 & 0.000 & -0.001 & -0.003 & $-0.024^{*}$ & $-0.023^{*}$ & $-0.025 * *$ & $-0.026^{*}$ \\
\hline & $(-0.083)$ & $(0.043)$ & $(-0.146)$ & $(-0.231)$ & $(-1.929)$ & $(-1.826)$ & $(-2.038)$ & $(-1.766)$ \\
\hline \multirow[t]{2}{*}{$\log$ (\# Stocks in equity portfolio } & $-0.030 * *$ & $-0.031^{* *}$ & $-0.028 * *$ & $-0.030 * *$ & $-0.041^{* *}$ & $-0.042 * *$ & $-0.038 * *$ & $-0.040 * *$ \\
\hline & $(-2.126)$ & $(-2.239)$ & $(-2.026)$ & $(-1.975)$ & $(-2.334)$ & $(-2.372)$ & $(-2.133)$ & $(-2.146)$ \\
\hline \multirow[t]{2}{*}{ Fund flows / lag(AUM) (\%) } & & & & 0.281 & & & & -0.002 \\
\hline & & & & $(0.841)$ & & & & $(-0.007)$ \\
\hline \multirow[t]{2}{*}{ I(Bad month) } & & 0.062 & $0.082 * *$ & $0.086^{* *}$ & & $0.161^{* * *}$ & $0.189 * * *$ & $0.211 * * *$ \\
\hline & & $(1.594)$ & $(2.173)$ & $(2.123)$ & & (3.076) & (3.653) & $(3.663)$ \\
\hline \multirow[t]{2}{*}{ YTD performance Q2 } & 0.017 & & 0.033 & 0.020 & -0.032 & & 0.004 & 0.017 \\
\hline & $(0.485)$ & & $(0.976)$ & $(0.563)$ & $(-0.790)$ & & $(0.110)$ & $(0.394)$ \\
\hline \multirow[t]{2}{*}{ YTD performance Q3 } & -0.015 & & 0.005 & 0.003 & -0.041 & & 0.005 & 0.025 \\
\hline & $(-0.433)$ & & $(0.157)$ & $(0.078)$ & $(-0.984)$ & & $(0.125)$ & $(0.576)$ \\
\hline \multirow[t]{2}{*}{ YTD performance Q4 } & 0.017 & & 0.038 & 0.015 & 0.014 & & 0.063 & 0.071 \\
\hline & $(0.47$ & & $(1.097)$ & $(0.399)$ & $(0.320)$ & & (1.544) & (1.593) \\
\hline \multirow[t]{2}{*}{ YTD performance Q5 } & $0.083^{* *}$ & & $0.104 * * *$ & $0.095^{* *}$ & $0.090 * *$ & & $0.139 * * *$ & $0.162 * * *$ \\
\hline & $(2.060)$ & & $(2.638)$ & $(2.198)$ & $(2.030)$ & & (3.212) & (3.403) \\
\hline Calendar quarter FE & Yes & Yes & Yes & Yes & Yes & Yes & Yes & Yes \\
\hline Observations & 6,598 & 6,598 & 6,598 & 5,710 & 6,598 & 6,598 & 6,598 & 5,710 \\
\hline Adjusted $\mathrm{R}^{2}$ & 0.702 & 0.702 & 0.702 & 0.700 & 0.549 & 0.549 & 0.550 & 0.542 \\
\hline
\end{tabular}




\section{Table 9. Manipulations and Incentives to Attract Attention}

The table reports fund-level OLS regressions of volatility-adjusted quarter-end "blips" of hedge fund portfolios. Specifically, the dependent variable, Blip/Volatility is defined for each fund-quarter as the difference between ret(last day) and ret(last day +1 ) divided by the daily volatility of the portfolio over the quarter. ret(last day) is the return of this portfolio on the last trading day of the quarter and ret(last day +1$)$ is the return of the same portfolio on the next trading day. The determinants are: the log of dollar long equity holdings reported in the $13 \mathrm{~F}(\log (A U M))$, the log of the number of stocks reported in the 13F (log(Equity portfolio size)), asset net flows as a percentage of lagged AUM (Fund flows / lag(AUM) (\%)), a dummy variable (I(Bad month)) for whether the current month's performance is below -2\%, and YTD performance (as of quarter's end) by quintiles (YTD performance quintile X). Year-to-date performance is interacted with three characteristics: whether the fund's age is below median (dummy Young), whether the YTD performance as of last quarter was in the lower two quintiles (dummy Low reputation) and whether the current month is March (dummy March).The universe is all TASS hedge funds for 2000Q1 to 2009Q4, for which the 13F is known. t-statistics are reported in parentheses. ${ }^{* * *},{ }^{* *}$, and ${ }^{*}$ denote statistical significance at the $1 \%, 5 \%$, and $10 \%$ levels, respectively. Standard errors are clustered at the fund level and timefixed effects are included.

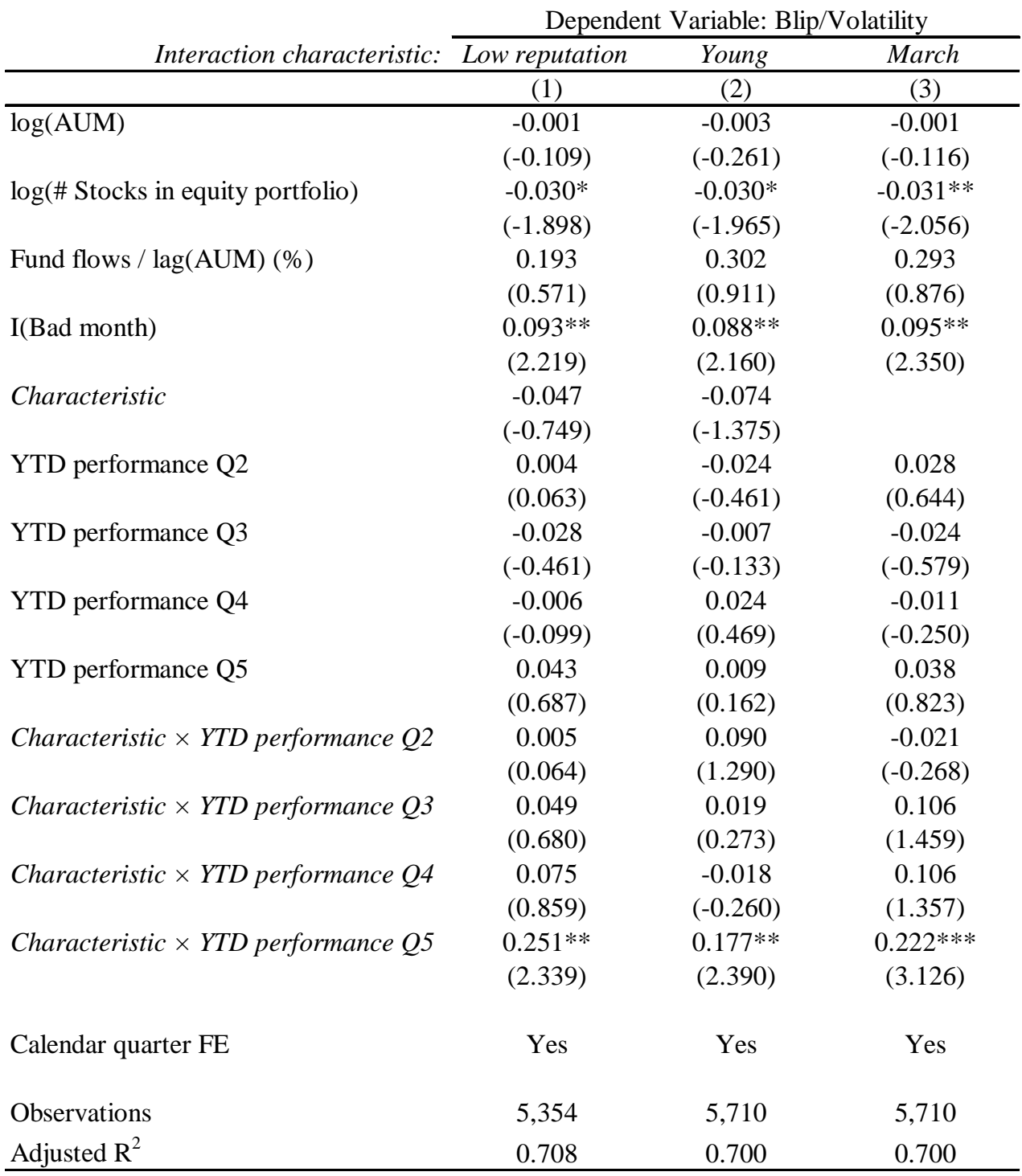




\section{Table 10. Stock Price Manipulation and Market Direction}

The table reports OLS regressions of the monthly average of quarter-end "blips" of hedge fund portfolios (marketadjusted and volatility and market-adjusted). Specifically, the dependent variable is the monthly average across hedge funds of AdjBlip and AdjBlip/Volatility. These variables are constructed for all TASS hedge funds for 2000Q1 to 2009Q4, for which the 13F is known in the following manner: Adj ret (last day) is the market-adjusted return of this portfolio on the last trading day of the quarter and Adj ret (last day - 1) (and respectively Adj ret (last day +1 )) are the returns of the same portfolio on the next (respectively previous) trading day. Adj Blip is defined at the fund level as the difference between Adj ret (last day) and Adj ret (last day + 1). The right-hand-side variable Qtr market returns is the value-weighted market portfolio over the last quarter and I(mkt below median) is a dummy equal to one if the market portfolio's performance is below its median during the sample period (1.06\%). $t$-statistics are reported in parentheses. ${ }^{* * *},{ }^{* *}$, and ${ }^{*}$ denote statistical significance at the $1 \%, 5 \%$, and $10 \%$ levels, respectively.

\begin{tabular}{lccccc} 
& \multicolumn{2}{c}{ Dep.: Adj. Blip } & & Dep.: Blip/Volatility \\
\cline { 2 - 3 } \cline { 5 - 6 } & $(1)$ & $(2)$ & & $(3)$ & $(4)$ \\
\hline Qtr market returns & $-0.063^{* * *}$ & & & $-2.665^{* *}$ & \\
& $(-2.786)$ & & & $(-2.419)$ & \\
I(mkt below median) & & $0.004^{* *}$ & & $0.226^{* *}$ \\
& & $(2.103)$ & & $(2.305)$ \\
Constant & $0.006^{* * *}$ & $0.004^{* *}$ & & $0.305^{* * *}$ & $0.200^{* * *}$ \\
& $(5.678)$ & $(2.536)$ & & $(6.241)$ & $(2.916)$ \\
Observations & & & & \\
Adjusted $\mathrm{R}^{2}$ & 39 & 39 & & 39 & 39 \\
\hline
\end{tabular}




\section{Table 11. Serial Manipulation? Autocorrelation of Abnormal Quarter-End Blips}

The table reports fund-level OLS regressions of volatility-adjusted quarter-end "blips" of hedge fund portfolios. Specifically, the dependent variable, Blip/Volatility, is defined for each fund-quarter as the difference between ret(last day) and ret(last day +1 ) divided by the daily volatility of the portfolio over the quarter. ret(last day) is the return of this portfolio on the last trading day of the quarter and ret(last day +1$)$ is the return of the same portfolio on the next trading day. Lag(Blip/Volatility) is defined for each fund as last quarter's measure of Blip/Volatility. The universe is all TASS hedge funds for 2000Q1 to 2009Q4, for which the 13F is known. $t$-statistics are reported in parentheses. $^{* * * *}{ }^{* *}$, and ${ }^{*}$ denote statistical significance at the $1 \%, 5 \%$, and $10 \%$ levels, respectively. Standard errors are clustered at the date level and time-fixed effects are included.

Dependent Variable: Blip/Volatility

\begin{tabular}{lccc} 
& $(1)$ & $(2)$ & $(3)$ \\
\hline lag(Blip / Volatility) & $0.123^{* * *}$ & $0.120^{* * *}$ & $0.113^{* * *}$ \\
$\log ($ AUM) & $(11.925)$ & $(11.509)$ & $(6.753)$ \\
log(\# Stocks in equity portfolio & & -0.005 & -0.005 \\
& & $(-0.976)$ & $(-0.557)$ \\
I(Bad month) & $-0.030^{* * *}$ & $-0.026^{* *}$ \\
& & $(-4.101)$ & $(-2.129)$ \\
YTD performance Q2 & & $0.092^{* *}$ \\
YTD performance Q3 & & & $(2.512)$ \\
YTD performance Q4 & & & 0.029 \\
YTD performance Q5 & & & $(0.871)$ \\
& & & 0.013 \\
Constant & & & $(0.412)$ \\
& & & 0.050 \\
Observations & & & $(1.460)$ \\
Adjusted R & & & $0.085^{* *}$ \\
\hline
\end{tabular}




\section{Figure 1. Intraday Cumulative Returns}

The figure reports the cumulative intraday returns (expressed as percentages) for stocks that have above- and belowmedian hedge fund ownership in the quarter. The two panels focus on the last day of the quarter and the first day of the next quarter, respectively. The sample period is 2000Q1 to 2009Q4.

\section{Figue1a: Last Day of the Month}

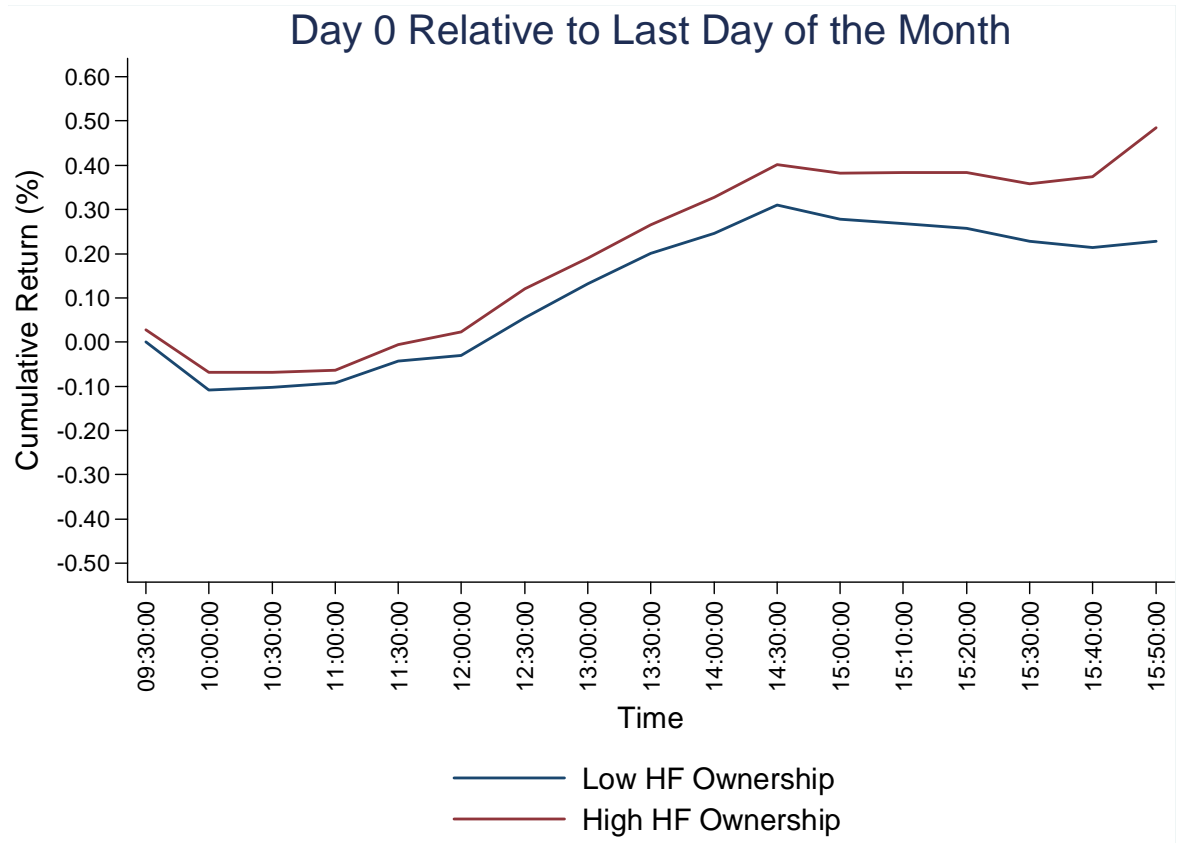

\section{Figue1b: First Day of the Month}

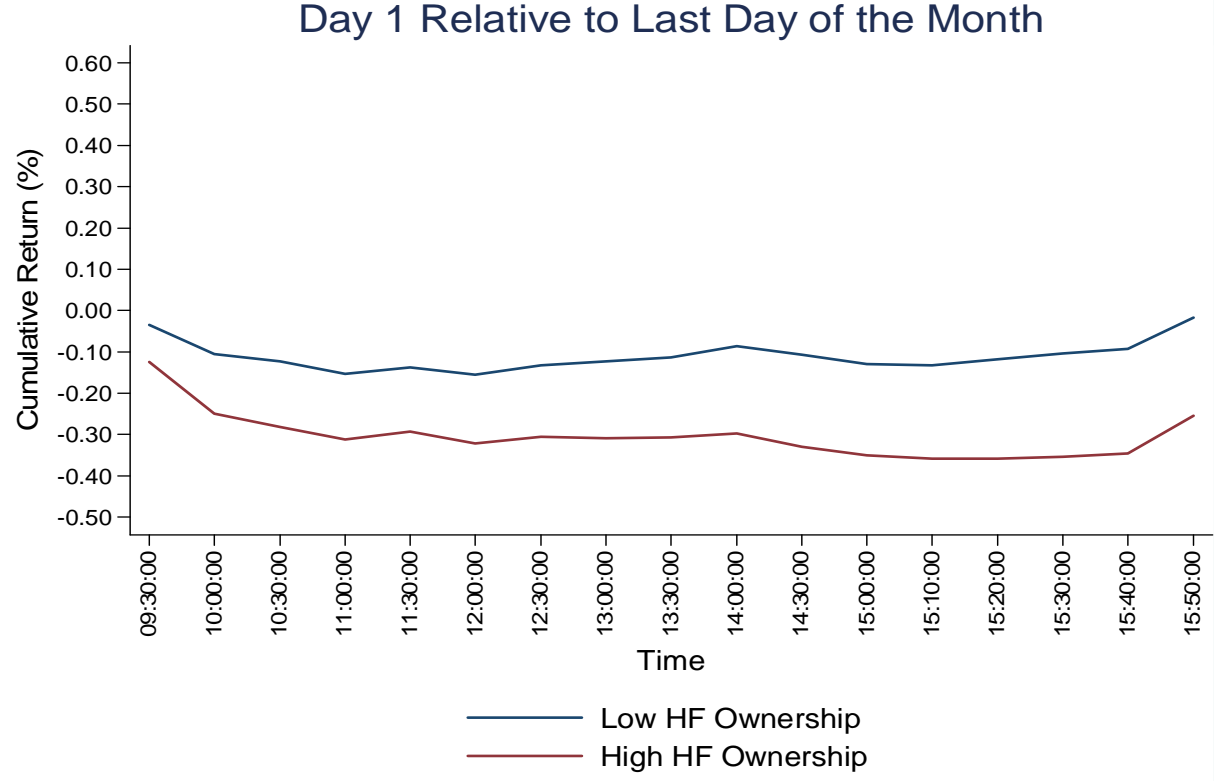


Figure 2. Time-Series of the Returns in the Last Day of the Quarter

The chart presents the time series average adjusted returns for stocks with high and low holdings by hedge funds. The sample period is 2000Q1 to 2009Q4.

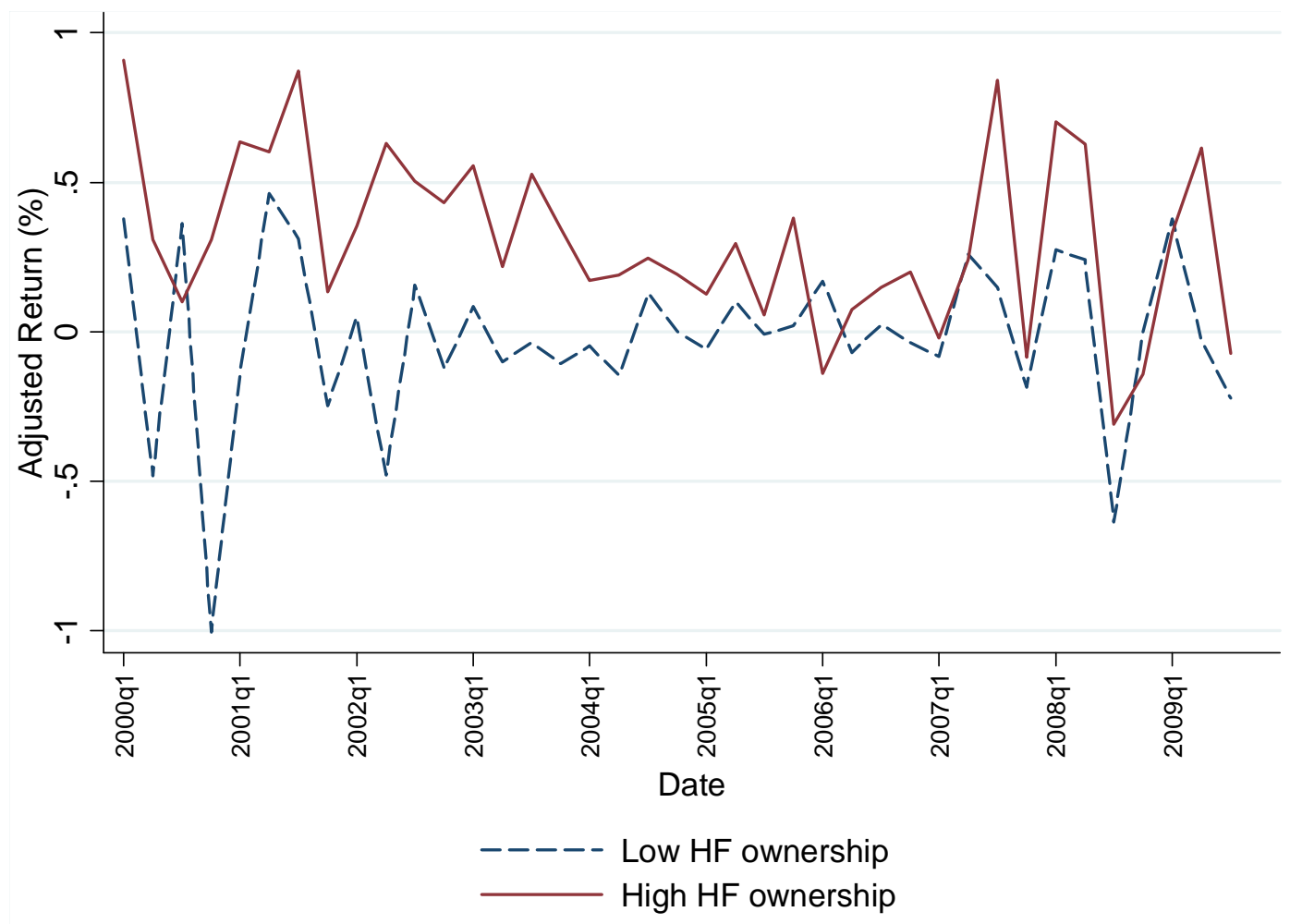




\section{Figure 3. Blip and Market Returns}

The figure presents the adjusted blip (last day-of-the-month returns minus first day-of-the-month returns, adjusted for market returns) as a function of quarterly stock market returns. The sample period is 2000Q1 to 2009Q4.

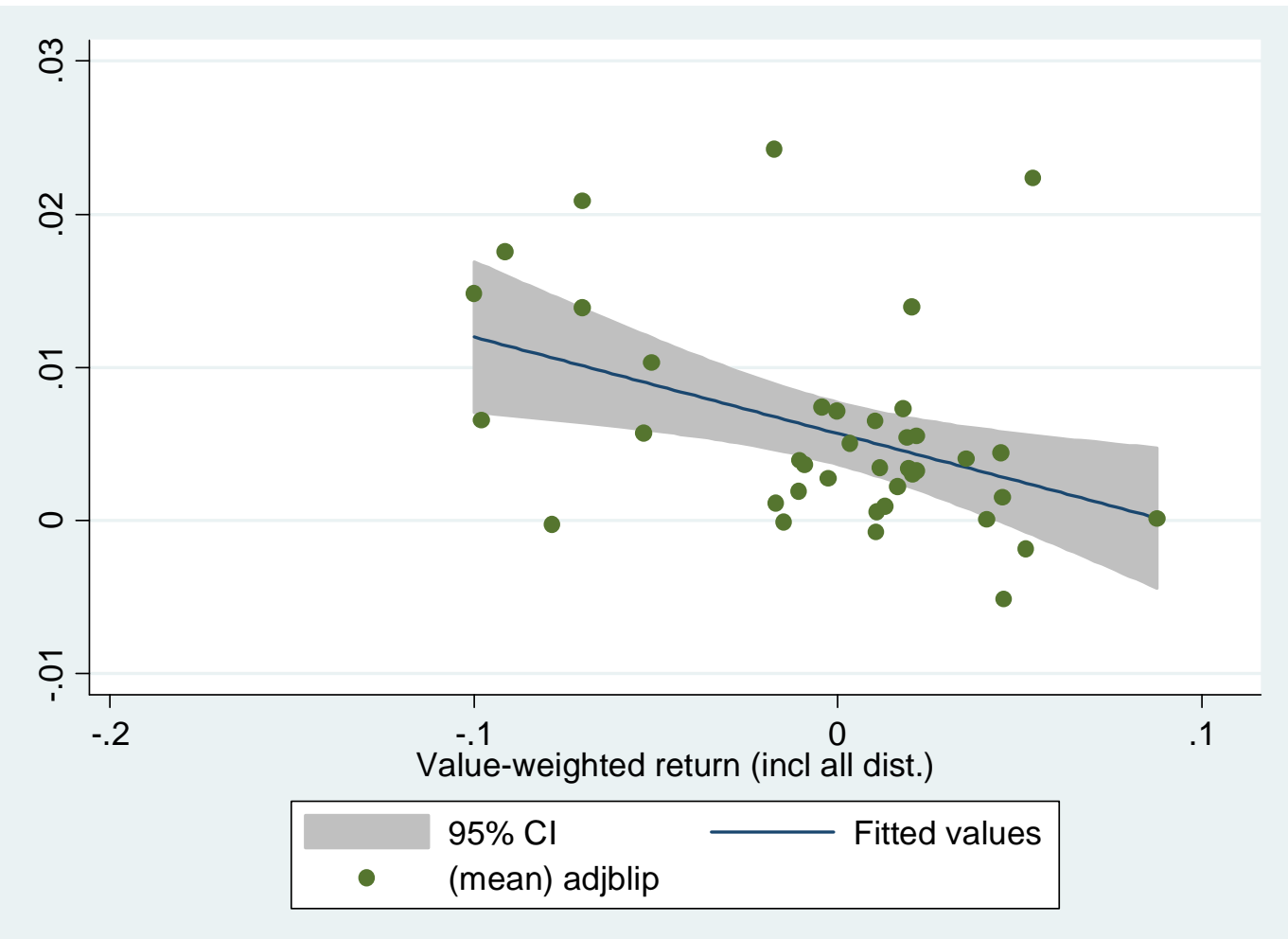




\section{Figure 4. Dollar Volume Needed to Move the Price by $1 \%$}

The figure presents results from a regression of second-level regressions of returns (expressed as percentages) on the signed dollar volume. The regressions are run for each group of Amihud (2002) decile stocks, for each second of the last 11 last seconds of trade. Only the last days of the month are included for all months from January 2000 through December 2009. The figure presents the inverse of the coefficient on the signed volume. It represents the dollar amount associated with a move of one percent in the price.

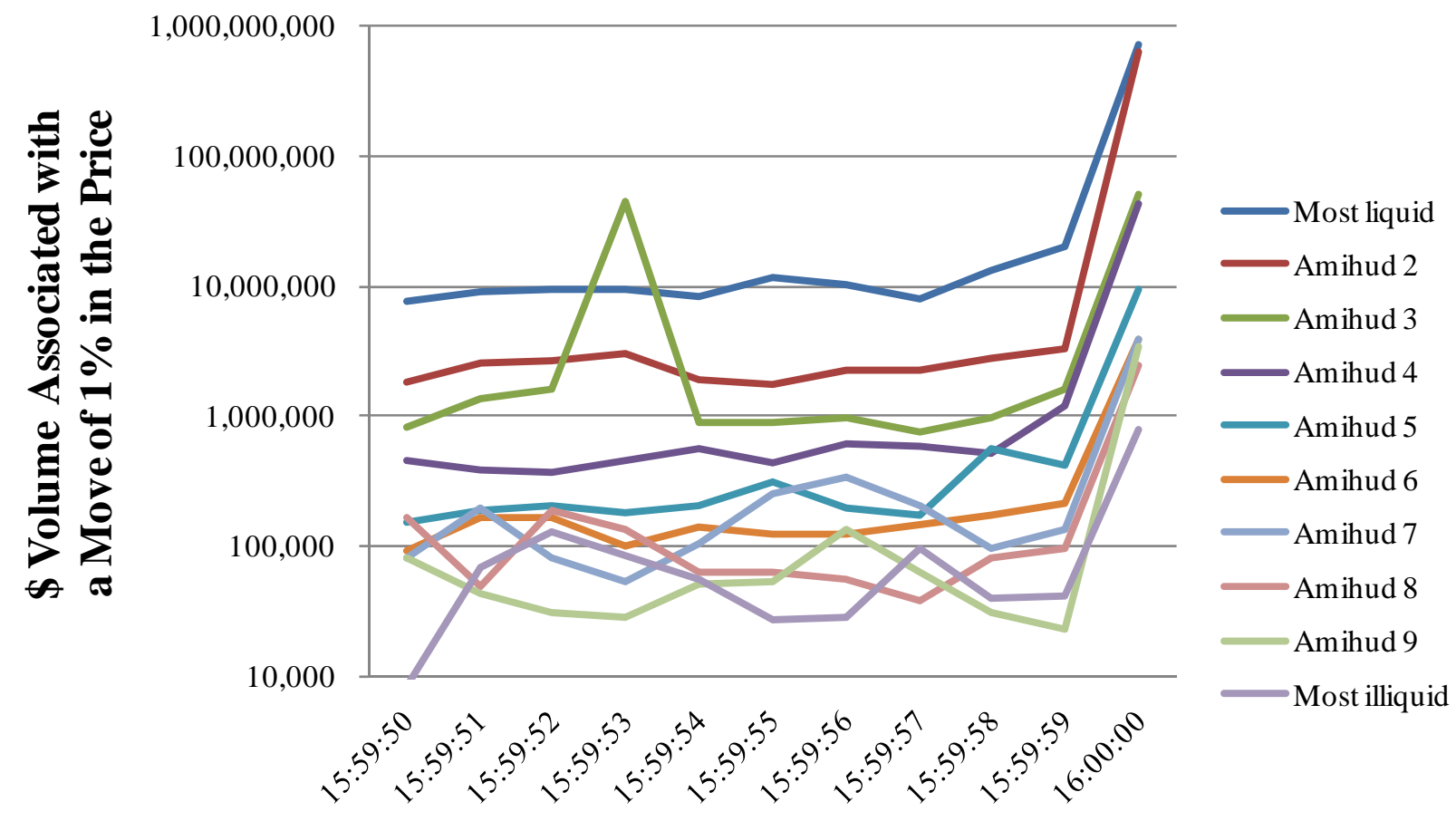

Time 


\section{Appendix Table 1. Robustness: Current Relative Performance Control}

The table reports fund-level OLS regressions similar to Tables 8. We add a new control: the current month's relative performance reported by quintiles of monthly performance. For the last month of all quarters, rank5_ytd is the quintile of the monthly performance of the fund for this month. The universe is all TASS hedge funds for 2000Q1 through 2009Q4 for which the 13F is known. T-statistics are reported in parentheses. ${ }^{* * *},{ }^{* *}$, and * denote statistical significance at the $1 \%, 5 \%$, and $10 \%$ levels, respectively. T-stats are clustered at the fund level; time fixed-effects are included.

Dependent Variable: Blip/Volatility

\begin{tabular}{|c|c|c|c|c|c|c|}
\hline & & & & \\
\hline & (1) & (2) & (3) & (4) & (5) & (6) \\
\hline \multirow[t]{2}{*}{$\log (\mathrm{AUM})$} & -0.001 & -0.002 & -0.003 & $-0.023^{*}$ & $-0.025^{* *}$ & $-0.025^{*}$ \\
\hline & $(-0.056)$ & $(-0.164)$ & $(-0.237)$ & $(-1.854)$ & $(-2.013)$ & $(-1.729)$ \\
\hline \multirow[t]{2}{*}{$\log (\#$ Stocks in equity portfolio) } & $-0.030^{* *}$ & $-0.028 * *$ & $-0.030^{* *}$ & $-0.041^{* *}$ & $-0.038 * *$ & $-0.040 * *$ \\
\hline & $(-2.136)$ & $(-2.020)$ & $(-1.972)$ & $(-2.352)$ & $(-2.165)$ & $(-2.188)$ \\
\hline \multirow[t]{2}{*}{ Fund flows / lag(AUM) (\%) } & & & 0.275 & & & -0.016 \\
\hline & & & $(0.823)$ & & & $(-0.042)$ \\
\hline \multirow[t]{2}{*}{ I(Bad month) } & & $0.111^{* * *}$ & $0.103^{* *}$ & & $0.211^{* * *}$ & $0.227^{* * *}$ \\
\hline & & $(2.606)$ & $(2.216)$ & & $(3.921)$ & $(3.745)$ \\
\hline \multirow[t]{2}{*}{ YTD performance Q2 } & 0.017 & 0.027 & 0.017 & -0.025 & -0.007 & 0.005 \\
\hline & $(0.492)$ & $(0.788)$ & $(0.457)$ & $(-0.618)$ & $(-0.167)$ & $(0.115)$ \\
\hline \multirow[t]{2}{*}{ YTD performance Q3 } & -0.009 & -0.000 & 0.000 & -0.026 & -0.009 & 0.011 \\
\hline & $(-0.269)$ & $(-0.010)$ & $(0.013)$ & $(-0.620)$ & $(-0.212)$ & $(0.244)$ \\
\hline \multirow[t]{2}{*}{ YTD performance Q4 } & 0.021 & 0.029 & 0.011 & 0.039 & 0.055 & 0.066 \\
\hline & $(0.567)$ & $(0.797)$ & $(0.261)$ & $(0.955)$ & (1.339) & $(1.467)$ \\
\hline \multirow{2}{*}{ YTD performance Q5 } & $0.085^{* *}$ & $0.091^{* *}$ & $0.089 * *$ & $0.130^{* * *}$ & $0.142^{* * *}$ & $0.172^{* * *}$ \\
\hline & $(2.049)$ & $(2.223)$ & $(1.979)$ & $(2.907)$ & $(3.185)$ & $(3.501)$ \\
\hline \multirow[t]{2}{*}{ Current performance Q2 } & 0.028 & $0.064 *$ & 0.047 & -0.013 & 0.056 & 0.059 \\
\hline & $(0.859)$ & (1.953) & (1.325) & $(-0.347)$ & (1.497) & $(1.478)$ \\
\hline \multirow[t]{2}{*}{ Current performance Q3 } & -0.032 & 0.019 & 0.001 & -0.030 & $0.067 *$ & 0.066 \\
\hline & $(-0.962)$ & $(0.551)$ & $(0.021)$ & $(-0.728)$ & (1.711) & (1.513) \\
\hline \multirow[t]{2}{*}{ Current performance Q4 } & 0.007 & 0.060 & 0.043 & $-0.075^{*}$ & 0.026 & 0.015 \\
\hline & $(0.192)$ & (1.566) & $(1.024)$ & $(-1.813)$ & $(0.678)$ & $(0.345)$ \\
\hline \multirow[t]{2}{*}{ Current performance Q5 } & 0.002 & 0.056 & 0.029 & $-0.088^{* *}$ & 0.014 & -0.003 \\
\hline & $(0.042)$ & $(1.347)$ & $(0.661)$ & $(-2.087)$ & $(0.342)$ & $(-0.070)$ \\
\hline Calendar quarter FE & Yes & Yes & Yes & Yes & Yes & Yes \\
\hline Observations & 6,598 & 6,598 & 5,710 & 6,598 & 6,598 & 5,710 \\
\hline Adjusted $\mathrm{R}^{2}$ & 0.702 & 0.702 & 0.700 & 0.549 & 0.550 & 0.542 \\
\hline
\end{tabular}

